Pontifícia Universidade Católica $_{\text {a }}$

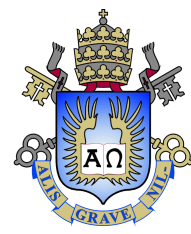

André Kenji Ikeuti

\title{
Roteamento do sistema de transporte intermodal de cargas
}

Dissertação de Mestrado

Dissertação apresentada como requisito parcial para obtenção do grau de Mestre (opção profissional) pelo Programa de Pósgraduação em Engenharia de Produção do Departamento de Engenharia Industrial da PUC-Rio.

Orientador: Prof. Rafael Martinelli 


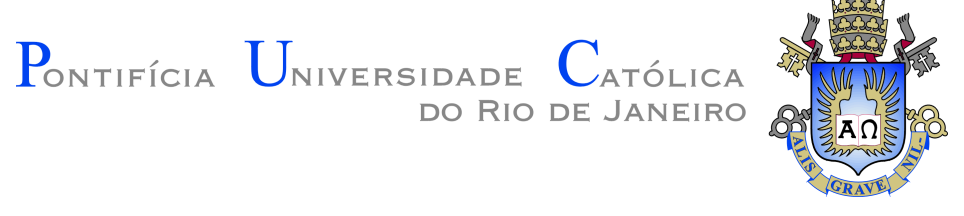

André Kenji Ikeuti

\title{
Roteamento do sistema de transporte intermodal de cargas
}

\begin{abstract}
Dissertação apresentada como requisito parcial para obtenção do grau de Mestre (opção profissional) pelo Programa de Pósgraduação em Engenharia de Produção do Departamento de Engenharia Industrial da PUC-Rio. Aprovada pela Comissão Examinadora abaixo assinada.
\end{abstract}

\author{
Prof. Rafael Martinelli \\ Orientador \\ Departamento de Engenharia Industrial - PUC-Rio
}

Prof. Anand Subramanian Universidade Federal da Paraíba - UFPB

Prof. Raphael Kramer Universidade Federal de Pernambuco - UFPE 
Todos os direitos reservados. É proibida a reprodução total ou parcial do trabalho sem autorização da universidade, do autor e do orientador.

\section{André Kenji Ikeuti}

Graduou-se em Administração, com ênfase em Administração Pública, pela Academia da Força Aérea em 2005. Após a graduação, ingressou no Programa de Pós-Graduação em Engenharia de Produção da PUC-Rio para obtenção do título de mestre.

Ficha Catalográfica

Ikeuti, André Kenji

Roteamento do sistema de transporte intermodal de cargas / André Kenji Ikeuti; orientador: Rafael Martinelli. - 2020.

v., 47 f: il. color. ; $30 \mathrm{~cm}$

Dissertação (mestrado) - Pontifícia Universidade Católica do Rio de Janeiro, Departamento de Engenharia Industrial, 2020.

Inclui bibliografia

1. Roteamento de veiculos. 2. Intermodal. 3. Programação inteira. I. Martinelli, Rafael. II. Pontifícia Universidade Católica do Rio de Janeiro. Departamento de Engenharia Industrial. III. Título. 


\section{Agradecimentos}

Agradeço à minha querida esposa Izandra que sempre esteve ao meu lado em todos os momentos de dificuldade durante os dois anos de dedicação quase que exclusiva ao curso, nos momentos de descanso.

Aos meus pais, Roberto e Cristina, meus heróis, me deram a formação de caráter e me ensinaram que o sucesso só se alcança a custo de muitas lágrimas e suor.

Ao meu orientador Rafael Martinelli que, mesmo sob condições completamente adversas, acreditou no meu potencial e aceitou me orientar nesta dissertação, prestando apoio incondicional mesmo nos finais de semana e feriados. O senhor se tornou um grande exemplo de dedicação e competência para mim.

Aos meus colegas de mestrado, com muito companheirismo, união e amizade, a turma de 2018/2 foi digna de elogios por todos os professores que nos lecionaram, pelo comprometimento e resiliência. Graças à vocês, comparecer à PUC-Rio 3 vezes por semana após um dia inteiro de trabalho, por 2 anos, tornou-se uma atividade prazerosa.

À Força Aérea Brasileira, que me proporcionou a oportunidade de cursar o Mestrado Profissional em Logística, que, além do suporte financeiro, deu todas as condições necessárias para que realizasse o curso em conjunto com as minhas atribuições profissionais.

Finalmente, à PUC-Rio, a qual parabenizo todos os professores e funcionários em nome do professor Márcio Thomé, coordenador do curso e nosso professor de Gerência de Operações, pela estrutura disponibilizada e pela organização do curso que, mesmo com diversos contratempos, foi conduzido com maestria.

O presente trabalho foi realizado com apoio da Coordenação de Aperfeiçoamento de Pessoal de Nível Superior - Brasil (CAPES) - Código de Financiamento 001. 


\section{Resumo}

Ikeuti, André Kenji; Martinelli, Rafael. Roteamento do sistema de transporte intermodal de cargas. Rio de Janeiro, 2020. 47p. Dissertação de Mestrado - Departamento de Engenharia Industrial, Pontifícia Universidade Católica do Rio de Janeiro.

Com o advento do comércio eletrônico, o mercado passou a atuar cada vez mais intensamente através de suas fronteiras geográficas e, como consequência, as empresas necessitam constantemente de inovações e melhorias na gestão de suas operações para se manterem competitivas. Desta forma, encontrar soluções de fretes que consigam atender longas distâncias em um curto prazo pode ser tão decisivo quanto o fator custo, por isso, os estudos acadêmicos em otimização de rotas intermodais estão em contínua evolução para se aproximarem dos modelos reais. Nesse contexto, esta dissertação busca solucionar um problema de roteamento aeroterrestre de transporte de cargas, com linhas aéreas predeterminadas e frotas próprias e heterogêneas. Uma extensão do problema de roteamento de veículos é elaborada com a inclusão de arcos que representam as possíveis linhas aéreas. O modelo é aplicado em um resolvedor de Programação Linear Inteira Mista e, primeiramente, é realizado um teste de validação com demandas fictícias em todos os locais. Em seguida, o modelo é aplicado no planejamento real de um órgão governamental em três períodos distintos. São realizadas análises sobre a velocidade de solução; a decisão de utilizar o modal aéreo, terrestre ou intermodal; e sobre os ganhos do modelo. Em comparação com as rotas efetivamente realizadas, o modelo traz redução de $7 \%$ a $55 \%$ dos custos com transportes. Com esses resultados, conclui-se que é imprescindível que os detentores de frota própria de aeronaves e caminhões utilizem o modal aéreo apenas como atividades acessórias, ou seja, que estejam cumprindo outras missões em conjunto (transporte de passageiros, por exemplo), ou para atender locais remotos.

\section{Palavras-chave}

Roteamento de veiculos; Intermodal; Programação inteira. 


\section{Abstract}

Ikeuti, André Kenji; Martinelli, Rafael (Advisor). Intermodal cargo transportation system's routing. Rio de Janeiro, 2020. 47p. Dissertação de Mestrado - Departamento de Engenharia Industrial, Pontifícia Universidade Católica do Rio de Janeiro.

With the advent of e-commerce, the market has started to act more and more intensively across its geographic borders and, as a consequence, companies constantly need innovations and improvements in the management of their operations in order to remain competitive. Thus, finding freight solutions that can serve long distances in the short term can be as decisive as the cost factor, for this reason, academic studies in intermodal routing optimization are continually evolving to approach real models. In this context, this thesis seeks to solve a problem of air-land cargo routing, with predetermined airlines and their own heterogeneous fleets. We elaborated an extension of the vehicle routing problem by including arcs that represent overhead lines. The model is applied to a Mixed Integer Linear Programming solver and, firstly, a validation test is performed with fictitious demands in all locations. It is then applied to the actual planning of a government agency in three different periods. We performed analyses on the solution speed; the decision to use the air, land or intermodal modal; and about the earnings of the model. In comparison with the routes actually carried out, the model reduces transport costs by $7 \%$ to $55 \%$. With this results, it is concluded that it is essential that owners of their aircraft and trucks fleet use the air modal only as secondary activities, in other words, that they are fulfilling more missions together (transportation of passengers, for example), or to deliver to remote locations.

\section{Keywords}

Vehicle routing Intermodal Integer programming 


\section{Sumário}

1 Introdução $\quad 10$

2 Referencial Teórico $\quad 14$

2.1 Transporte aeroterrestre de cargas 14

2.2 Problema de Roteamento de Veículos 17

2.2.1 VRP com frota heterogênea 18

$\begin{array}{ll}2.2 .2 \text { VRP multicommodity } & 18\end{array}$

2.3 Eliminação de Subciclos do VRP 19

2.3.1 Restrição de Eliminação de Subciclos 20

2.3.2 Miller-Tucker-Zemlim 21

2.4 Algoritmos de solução do VRP 21

2.4.1 Heurísticas e Meta-heurísticas 22

2.4.2 Métodos Exatos 23

3 Metodologia $\quad 24$

3.1 Descrição do Problema 24

$\begin{array}{lll}3.1 .1 & \text { Linhas Aéreas } & 24\end{array}$

3.1.2 Transbordo 24

3.1.3 Descrição do Modelo 25

$\begin{array}{lll}3.2 & \text { Premissas } & 26\end{array}$

3.3 Formulação do Modelo 27

$4 \quad$ Estudo de caso $\quad \mathbf{2 9}$

4.1 Descrição do Caso 29

4.2 Simplificações 31

4.3 Coleta e Tratamento dos Dados 32

4.3.1 Custos Aéreos 33

4.3.2 Custos Terrestres 33

4.3.3 Demanda 34

4.3.4 Rotas Efetivamente Realizadas 35

5 Resultados $\quad 37$

$\begin{array}{lll}5.1 & \text { Aplicação } & 37\end{array}$

5.2 Velocidade e análise de viabilidade 37

5.3 Comparação dos Resultados 38

5.4 Discussões 41

6 Conclusão 43 


\section{Lista de figuras}

Figura 1.1 Representação gráfica da evolução do transporte de cargas no Brasil

Figura 1.2 Rede de transporte intermodal 11

$\begin{array}{lll}\text { Figura 1.3 Custos logísticos em relação ao PIB brasileiro } & 12\end{array}$

Figura 1.4 Exemplo Fictício 13

$\begin{array}{lll}\text { Figura 2.1 Panorama de operações aeroterrestres } & 15\end{array}$

$\begin{array}{lll}\text { Figura 2.2 Exemplo de um subciclo. } & 19\end{array}$

Figura 2.3 Atuação do SEC. 20

$\begin{array}{lll}\text { Figura 3.1 Exemplo de linhas aéreas } & 25\end{array}$

Figura 3.2 Transbordo entre uma aeronave e um caminhão 26

$\begin{array}{lll}\text { Figura 4.1 Mapa completo. } & 29\end{array}$

Figura 4.2 Mapa das LAP. 31

Figura 5.1 Representação gráfica dos custos totais das rotas. 41 


\section{Lista de tabelas}

Tabela 2.1 Resumo dos principais estudos de operações aeroterrestres 16

$\begin{array}{lll}\text { Tabela 2.2 Tendências de pesquisas em VRP. } & 17\end{array}$

$\begin{array}{lll}\text { Tabela } 4.1 & \text { Descrição das LAP. } & 30\end{array}$

Tabela 4.2 Especificações das aeronaves.

Tabela 4.3 Especificações dos caminhões. 34

Tabela 4.4 Especificações das demandas. 35

Tabela 4.5 Rotas efetivamente realizadas. 36

Tabela 5.1 Resultados do modelo com demandas aleatórias. 38

Tabela 5.2 Fluxo do pedido 39

Tabela 5.3 Custos resultantes do modelo. 39

Tabela 5.4 Ganhos do modelo em relação às rotas efetivamente realizadas. $\quad 40$

Tabela 5.5 Quantidade de locais atendidos por modal. 41

Tabela 5.6 Comparação entre as rotas otimizadas e realizadas do Período 1 (para $\mathrm{FC}=10 \%$ ) 


\section{Introdução}

O transporte internacional de cargas via modal aéreo está em constante crescimento nas últimas décadas (Huang et al. 2020). Esse protagonismo surgiu a partir do momento em que as empresas passaram a atuar no mercado global, em consonância com a modernização da gestão das operações que tornou favorável a relação entre custo e tempo do transporte aéreo (Feng et al. 2015, Archetti e Peirano 2020, Huang et al. 2020).

Além disso, Archetti e Peirano (2020) explicam o incremento da demanda por frete aéreo com advento do comércio eletrônico, que vem tornando o mercado cada vez mais competitivo e os clientes mais exigentes no quesito prazo de entrega e preço. No Brasil, segundo a Agência Nacional de Aviação Civil (2019), a demanda por transporte aéreo de cargas aumentou em 60\% de 2009 a 2018, conforme Figura 1.1.

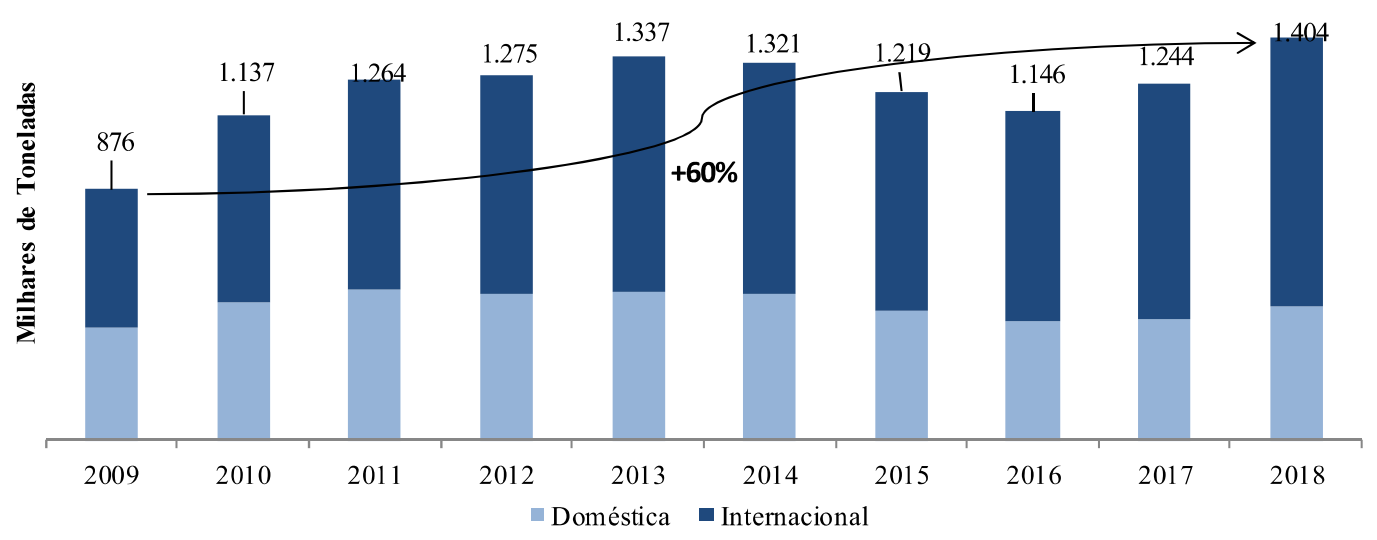

Figura 1.1: Representação gráfica da evolução do transporte de cargas no Brasil Fonte: Agência Nacional de Aviação Civil (2019)

A partir de então, conforme Huang et al. (2020), as transportadoras passaram a oferecer serviços complexos e de alto valor agregado, como a entrega porta-a-porta. Este serviço consiste na utilização de caminhões e aeronaves para a realização de entregas de mercadorias de um depósito para o cliente. De maneira geral, o produto é carregado em um caminhão até o aeroporto de origem, transportado por aeronave até o aeroporto de destino e, por fim, destinado ao cliente por outro caminhão. Nessas operações, o desafio é tomar 
as decisões de transporte para realizar as entregas com o menor custo possível, dentro de um limite de tempo. A Figura 1.2 ilustra o funcionamento de uma rede de serviços de transporte intermodal.

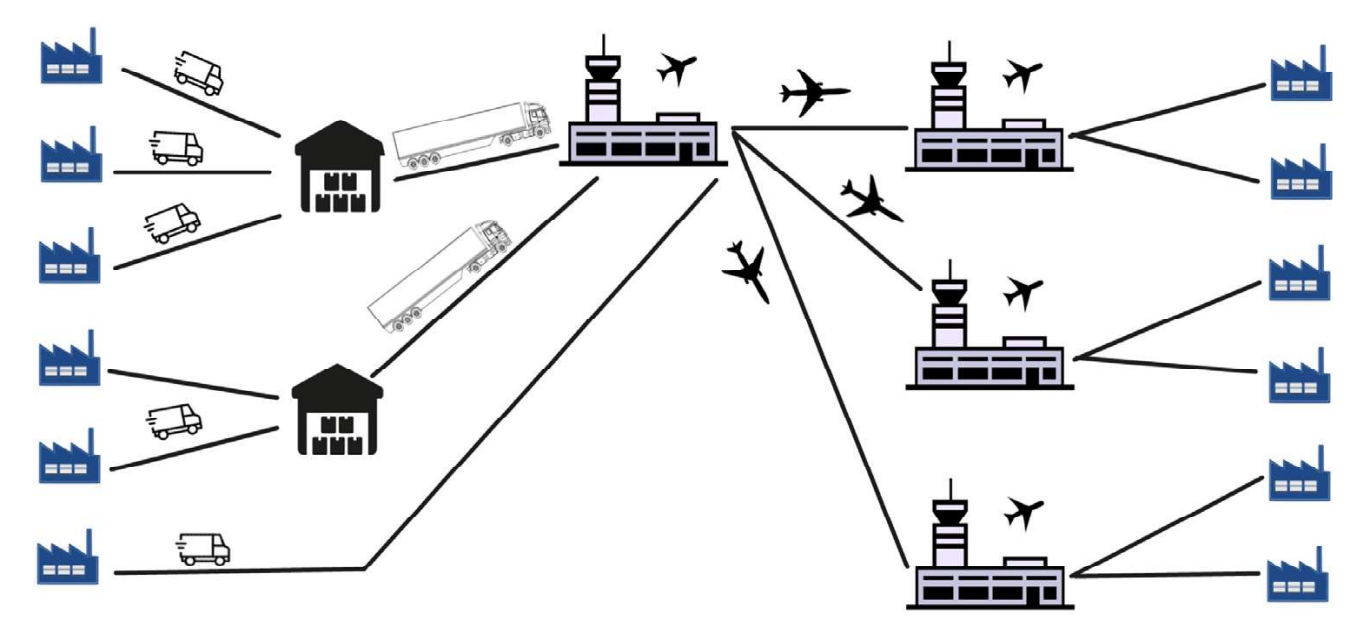

Figura 1.2: Rede de transporte intermodal

Fonte: Archetti e Peirano (2020)

Embora a literatura contemple uma ampla gama de modelos de otimização de rotas, o assunto está longe de ser esgotado devido à complexidade das operações reais, sobretudo quando abordam os transportes intermodais (Feng et al. 2015). Além das restrições presentes no Problema de Roteamento de Veículos, ou vehicle routing problem (VRP), as operações nos terminais aéreos envolvem custos variáveis de frete, economia de escala, carregamento de contêineres, dentre outros.

Sob outra perspectiva, de acordo com Gilmore (2002), os custos com transportes englobam uma grande fatia do total de custos da Cadeia de Suprimentos, portanto, um planejamento de otimização de rotas torna-se essencial para que as empresas se mantenham competitivas no mercado, sem o prejuízo de suas margens de lucro. Trazendo para o contexto nacional, de acordo com o Instituto de Logística e Supply Chain (2017), em 2015, os custos com transportes representaram 56,5\% dos custos logísticos totais e 6,9\% do Produto Interno Bruto (PIB) brasileiro, valor superior ao total investido na Educação $(6,2 \%)$ no mesmo ano, segundo o Instituto Nacional de Estudos e Pesquisas Educacionais Anísio Teixeira (2020). A Figura 1.3 contém um gráfico que ilustra a relevância dos custos de transportes frente aos custos logísticos totais.

O problema abordado nesta dissertação é o roteamento de um serviço de entrega porta-a-porta que possui um depósito único e diversos clientes. Para realizar os transportes, o despachante possui frota própria de caminhões, 


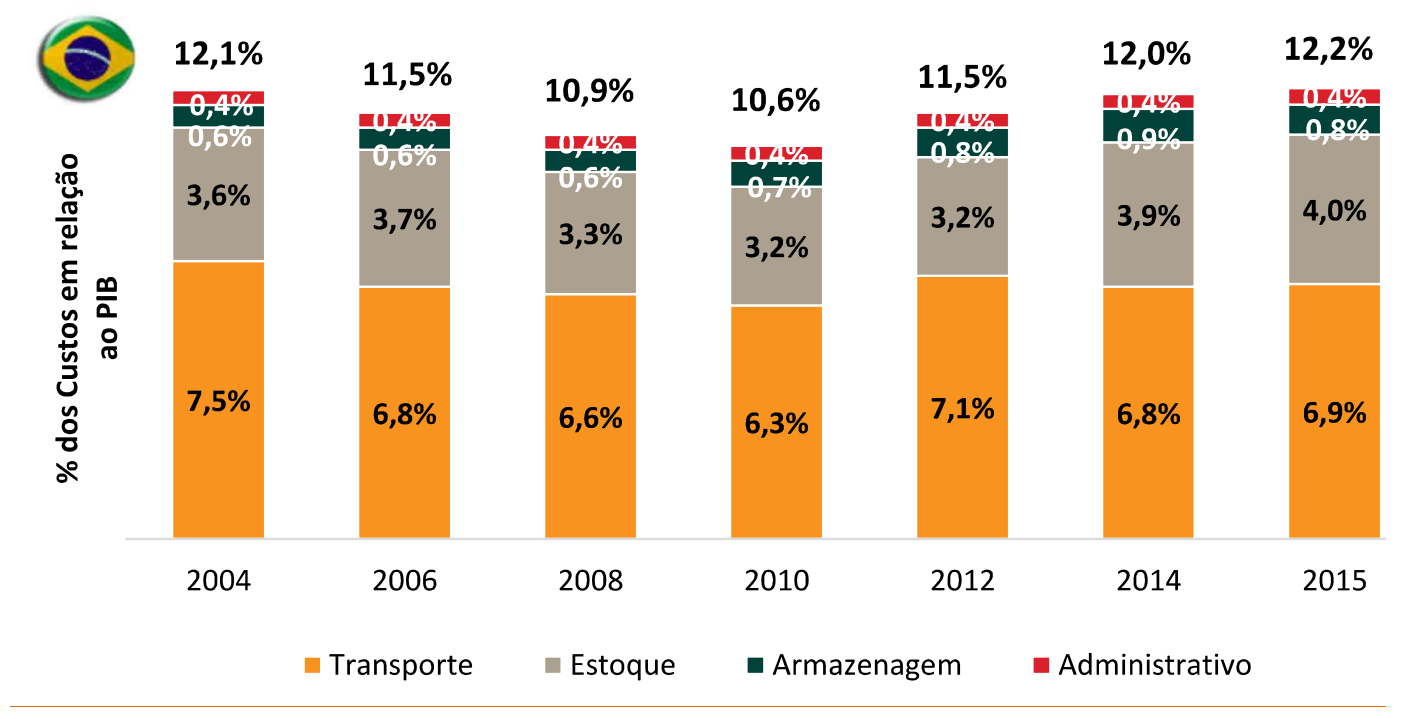

Figura 1.3: Custos logísticos em relação ao PIB brasileiro

Fonte: ILOS (2017)

localizadas no depósito, e de aeronaves que seguem rotas previamente planejadas. Enquanto a frota terrestre inicia seu trajeto do depósito e, obrigatoriamente, deve retornar a ele após a realização da última entrega; as aeronaves iniciam e encerram seus trajetos em aeroportos distintos. Há a possibilidade de transbordo de carga entre todos os veículos (caminhões e aeronaves).

A Figura 1.4 ilustra as possíveis rotas de um caso fictício que possui origem no ponto 1 e necessita realizar a entrega nos pontos 2 a 8 . A rota terrestre representa o caminhão que percorre os clientes $3,4,5,6$ e retorna ao depósito. A linha intermitente ilustra o trecho aéreo que inicia ponto 6 e atende os pontos 7 e 8, ao passo que a rota sólida consistente atende à demanda do ponto 2 , apenas. Os arcos mais claros $(1,3)$ e $(3,6)$ e os arcos mais finos $(3,5)$ e $(5,4)$, retratam rotas aéreas que estavam disponíveis para realizar o transporte, mas não foram utilizadas.

O problema apresentado, nomeado como heterogeneous air-land cargo routing problem with predetermined airlines (HALRPPA) é uma extensão do clássico Problema de Roteamento de Veículos, internacionalmente conhecido como VRP, com a inclusão de restrições que formam as linhas aéreas predefinidas (LAP) e que permitem a realização de entregas via aeronaves, caminhões, ou com a utilização dos dois modais mediante transbordos. O HALRPPA se diferencia do estudo atual de Huang et al. (2020) por possuir frota própria de caminhões, aeronaves e operadores de carga, em consequência, não são considerados os custos com as operações nos terminais.

Portanto, a proposta é modelar o HALRPPA e utilizar a Programação Linear Inteira Mista (MILP) para fornecer as rotas com custo mínimo e aplicá- 


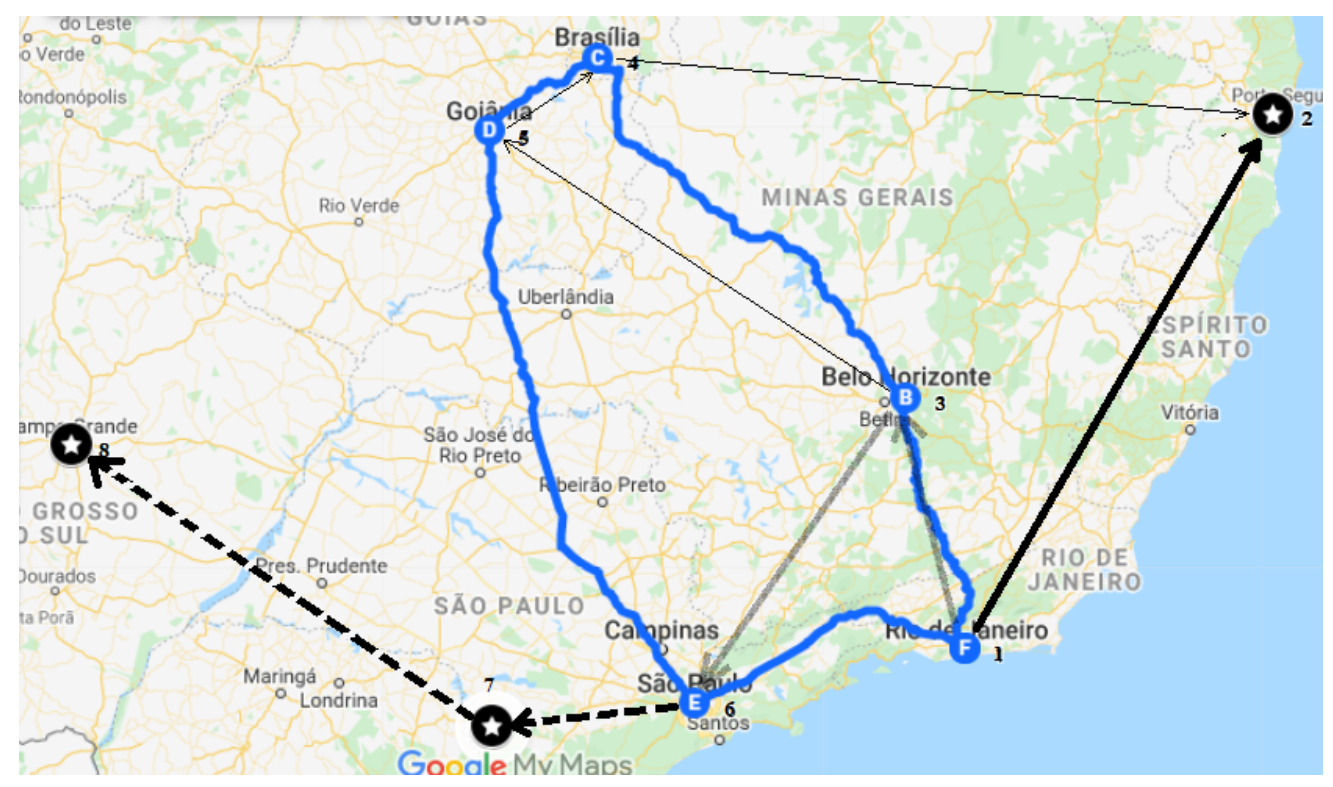

Figura 1.4: Exemplo Fictício

Fonte: $\mathrm{O}$ autor

lo em um caso real enfrentado por um órgão governamental para verificar os possíveis ganhos com a redução dos custos de transporte. Além disso, como objetivo secundário, procura-se estudar a ocasião em que o modal aéreo é mais econômico em relação ao terrestre.

O presente estudo está organizado em seis capítulos, incluindo este introdutório. No Capítulo 2, é apresentado o referencial teórico acerca do planejamento das operações aeroterrestres e dos modelos exatos de VRP. No Capítulo 3, é detalhada a metodologia adotada para o estudo. No Capítulo 4, consta o estudo de caso. No Capítulo 5, são demonstrados os resultados e as discussões do modelo ao aplicá-lo no caso e, por fim, o Capítulo 6, encerra o trabalho com as conclusões obtidas e as recomendações para futuros estudos. 


\section{2 \\ Referencial Teórico}

Neste capítulo são abordados os principais conceitos que embasaram o desenvolvimento do estudo em tela. A primeira seção introduz ao leitor o funcionamento das operações aeroterrestres. Em seguida, é apresentada a revisão literária acerca do VRP e suas principais variantes. A terceira seção descreve os algoritmos mais utilizados para a resolução do VRP. Ressalta-se que o objetivo aqui não é aprofundar nos assuntos abordados, mas sim, situar o leitor no estado da arte no roteamento aeroterrestre.

\section{1}

\section{Transporte aeroterrestre de cargas}

O transporte multimodal objetiva realizar um serviço de entrega de mercadorias porta-a-porta com a utilização de dois ou mais modais (aéreo, fluvial, cabotagem, ferrovia e estrada) sem interrupções (Chang 2008). De acordo com SteadieSeifi et al. (2014), a literatura aborda 4 tipos diferentes de operações envolvendo múltiplas categorias de veículos de carga:

- Multimodal: em sua versão mais básica, os bens são entregues por múltiplos modais em sequência, sem demais especificidades. A unidade de transporte não é determinada, podendo ser uma caixa, contêiner, baú de caminhão ou vagão de trem.

- Intermodal: um tipo específico de multimodal, no qual a unidade de carga não é manipulada durante a troca de modal, como ocorre nos transportes de contêineres de grande capacidade.

- Comodal: transporte multimodal com o foco na utilização eficiente dos recursos disponíveis e na maximização dos benefícios que cada modal possui. Essa modalidade implica a cooperação entre diversos operadores logísticos, através de um grupo ou consórcio que operam em cadeia.

- Sincromodal: o transporte sincromodal é uma evolução do comodal. Trata-se de uma estrutura integrada entre operadores logísticos que permite, de acordo com a conveniência dos clientes ou a circunstância dos operadores, a seleção do modal desejado para cada etapa do transporte, bem como a intercambialidade entre os modais durante o trajeto. 
No entanto, SteadieSeifi et al. (2014) salienta que o termo intermodal ainda é utilizado na literatura de maneira abrangente e que pode ser confundido entre os demais, principalmente com o multimodal. Por esse motivo, o estudo em tela será mencionado como intermodal por se tratar do termo mais presente nos trabalhos acadêmicos, embora ele seja aplicável tanto para um sistema multimodal ou comodal.

Sendo assim, o transporte intermodal aeroterrestre consiste na coleta de cargas por caminhões que as levam até o aeroporto de origem; o deslocamento do aeroporto de origem ao aeroporto de destino é realizado por aeronaves e, por fim, caminhões realizam o trecho aeroporto de destino até os clientes.

Segundo Feng et al. (2015), os principais atores envolvidos neste serviço são: i) remetentes, aqueles que necessitam enviar seus produtos para os mais diversos locais espalhados pelo mundo; ii) despachantes, atuam como um intermediário em todas as operações para coordenar o fluxo da carga desde a coleta até a entrega; iii) transportadores, responsáveis por transportar a carga via caminhões, aeronaves, navios ou trens; e iv) clientes ou destinatários, os que necessitam dos produtos dos remetentes. Kasilingam (2003) ilustra o funcionamento de uma operação aeroterrestre através da Figura 2.1.

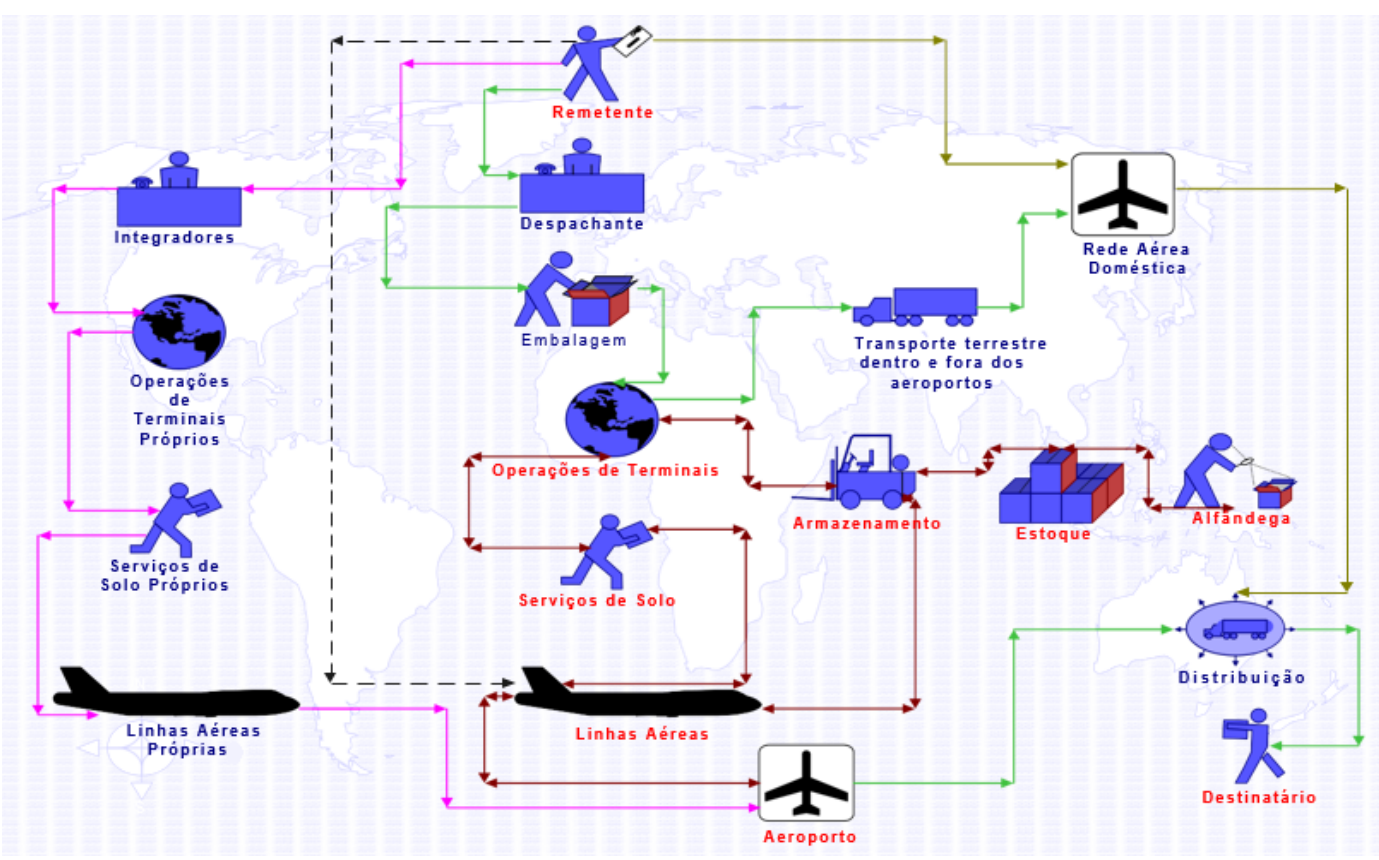

Figura 2.1: Panorama de operações aeroterrestres

Fonte: Adaptado de Kasilingam (2003)

De acordo com Li et al. (2012), o despachante de cargas aéreas, ou airfreight forwarder na língua britânica, é um dos pilares das operações nos terminais aeroportuários, pois eles precisam coletar e consolidar com precisão os volumes para o maior aproveitamento dos espaços disponíveis. 
O airfreight forwarder consolidation problem (AFCP) abordado por Huang e Chi (2007) é resolvido utilizando um MILP extremamente complexo e, assim como o VRP, também é um problema NP-difícil. Posteriormente, outras restrições foram incluídas ao AFCP, como o trabalho de Li et al. (2012), que inseriu janelas de tempo e economia de escala. Somando-se a isso, para o transportador intermodal, ainda há o desafio de consolidar as demandas tanto no aeroporto de origem, quanto no de destino para fins de se beneficiar na economia de escala (Archetti e Peirano 2020).

Além disso, Chang (2008) ressalta as seguintes dificuldades para a realização do roteamento internacional intermodal: i) multiplicidade de objetivos (minimização de tempo e/ou custo), de acordo com a prioridade do cliente; ii) a existência de janelas de tempo dos deslocamentos aéreos; e iii) a variação dos custos de transporte decorrentes da economia de escala.

A Tabela 2.1 resume os estudos mais recentes sobre operações aeroterrestres que serviram como base neste estudo. Na primeira coluna estão os autores e o ano de publicação. Na seguinte estão os escopos do trabalho, sendo que se dividem em: i) operação nos terminais, aqueles que focam na consolidação das demandas pelos despachantes de cargas aéreas; ii) Transporte Multimodal/Intermodal que é o mesmo escopo desta dissertação; iii) Frete Multimodal; e iv) Operações Aéreas de Cargas. Na terceira coluna estão os métodos utilizados na pesquisa.

Tabela 2.1: Resumo dos principais estudos de operações aeroterrestres

\begin{tabular}{lll}
\hline Artigo & Escopo & Método \\
\hline Huang e Chi (2007) & Operação nos terminais & $\begin{array}{l}\text { Heurística } \\
\text { com Relaxação Lagrangeana } \\
\text { Chang (2008) }\end{array}$ \\
& Transporte Multimodal & $\begin{array}{l}\text { Heurística } \\
\text { com Relaxação Lagrangeana }\end{array}$ \\
Leung et al. (2009) & Operação nos terminais & Heurística \\
& & com Branch-and-Bound \\
Yang et al. (2011) & Transporte Intermodal & Programação Multiobjetivo \\
Cho et al. (2012) & Transporte Intermodal & Programação Dinâmica \\
Li et al. (2012) & Operação nos terminais & Heurística \\
& & com Relaxação Lagrangeana \\
& & e Local Branching \\
SteadieSeifi et al. (2014) & Frete Multimodal & Revisão Literária \\
Feng et al. (2015) & Operações Aéreas de Carga & Revisão Literária \\
Archetti e Peirano (2020) & Transporte Intermodal & MILP \\
Huang et al. (2020) & Transporte Intermodal & Heurística \\
& & com Relaxação Lagrangeana \\
\hline
\end{tabular}




\section{2}

\section{Problema de Roteamento de Veículos}

O VRP foi introduzido inicialmente por Dantzig e Ramser (1959) em seu modelo mais simples, o VRP capacitado (CVRP), como uma extensão do Problema do Caixeiro Viajante, conhecido como Traveling Salesman Problem (TSP). O CVRP consiste na elaboração de rotas ótimas de veículos para o transporte de bens de um depósito para vários clientes, em que cada veículo está restrito a uma capacidade de carga (Laporte 2007). Por conseguinte, o CVRP busca minimizar a distância total percorrida, exigindo as seguintes premissas: as rotas iniciam e terminam no mesmo depósito; todos os locais, obrigatoriamente, devem ser visitados somente uma vez e; a demanda total de cada rota não pode exceder a capacidade do veículo que a executa.

Com o passar dos anos, diversas extensões do VRP foram elaboradas para retratar as numerosas variáveis contidas nos problemas reais. A revisão literária mais recente sobre o VRP foi realizada por Vidal et al. (2020), dividindo os estudos sob três perspectivas: i) objetivos ou a combinação de objetivos; ii) integração da otimização do roteamento com outras decisões de negócios; e iii) busca por modelos mais precisos e refinados. Os principais aspectos que foram objetos de estudo de Vidal et al. (2020) estão resumidos na Tabela 2.2.

Tabela 2.2: Tendências de pesquisas em VRP.

\begin{tabular}{ll}
\hline Perspectiva & Categorias de Problemas \\
\hline & Lucratividade \\
& Qualidade do Serviço \\
& Equilíbrio \\
& Consistência \\
Objetivos & Simplicidade \\
& Confiabilidade \\
& Externalidade \\
& Roteamento e Distritamento \\
& Roteamento e Localização de Facilidades \\
& Roteamento de Inventário \\
Integração com & Roteamento de Gerenciamento da Produção \\
decisões de negócio & Roteamento e Composição da Frota \\
& Especificidades da Rede de Transportes \\
& Especificidades dos Motoristas e Veículos \\
& Especificidades dos Requisitos dos Clientes \\
\hline \multirow{2}{*}{ Problemas refinados } &
\end{tabular}

Fonte: adaptado de Vidal et al. (2020)

Dentre as principais variantes do CVRP, participa do HALRPPA o problema de roteamento de veículos com frota heterogênea (HVRP), além do problema de roteamento de veículos com multicommodity. 


\subsection{1}

\section{VRP com frota heterogênea}

O dimensionamento da frota é um problema comum na indústria, iniciando-se pela decisão entre possuir uma frota própria ou terceirizar o transporte de cargas e, em sequência, na determinação da frota ideal (Koç et al. 2016).

O HFVRP, também conhecido como VRP de frota mista, é uma extensão do VRP que oferece a melhor composição da frota, através da minimização da soma dos custos fixos, ou seja, o valor predeterminado que é pago somente se o veículo for utilizado, por exemplo: custo de locação ou de aquisição); e dos custos variáveis, aqueles que são relativos à distância percorrida, como os combustíveis e manutenção dos veículos (Subramanian et al. 2012). As seguintes premissas devem ser consideradas: i) assim como no VRP clássico, cada cliente é visitado por exatamente uma rota; e ii) a quantidade de rotas é inferior à quantidade de veículos.

De acordo com Koç et al. (2016), as duas principais variantes do HFVRP são: i) Fleet Size and Mix Vehicle Routing Problem (FSM), de Golden et al. (1984), na qual a frota é considerada infinita, portanto, normalmente associada à otimização de aquisição de veículos (Irnich et al. 2014); e ii) Heterogeneous Fixed Fleet Vehicle Routing Problem (HF), introduzida por Taillard (1999), utilizada quando a frota é predeterminada. Posteriormente, surgiram variantes do HFVRP, como o Site-Dependent Vehicle Routing Problem (SDVRP), em que cada local necessita ser atendido por um tipo específico de veículo (Chao et al. 2016). Esse problema foi criado para modelar as demandas que possuem a necessidade de serem transportadas por caminhões de grandes capacidades.

Neste trabalho serão utilizadas as variantes: i) HF, por considerar que as operadoras de transporte aeroterrestres serão detentoras de frota própria, portanto, com quantidade finita de veículos; e ii) o SDVRP, pois haverá cargas com características peculiares que serão transportadas exclusivamente pelos veículos que estão habilitados a carregá-las, ou seja, haverá o problema de elegibilidade entre as cargas e caminhões.

\subsection{2}

\section{VRP multicommodity}

O fluxo de commodity no VRP foi inicialmente examinado por Gavish e Graves (1982) para modelar o movimento dos materiais durante as rotas, tendo aplicabilidade nos casos de roteamento de múltiplas categorias de produtos (Baldacci et al. 2004). O HALRPPA realiza o transporte de um único tipo 
de material, porém, a restrição de fluxo de commodity servirá para definir os transbordos de carga dos caminhões para as aeronaves.

\section{3}

\section{Eliminação de Subciclos do VRP}

Os subciclos são rotas que não estão conectadas entre si em um determinado grafo, conforme Ahuja et al. (1993) demonstra na Figura 2.2. No VRP, as soluções devem contemplar visitas em todos os nós através de rotas interligadas e originadas no depósito e, para tanto, há a necessidade de restrições que impeçam a formação dessas sub-rotas.
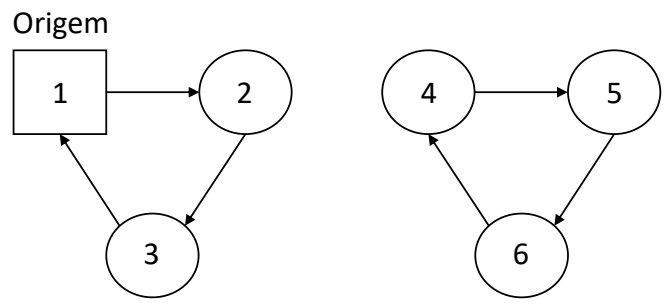

Figura 2.2: Exemplo de um subciclo.

Fonte: Adaptado de Ahuja et al. (1993)

Para exemplificar a formação de subciclos, será utilizada a formulação matemática de um problema simples de TSP sem as respectivas restrições de eliminação. Conforme Pataki (2003), seja $G=(N, A)$ um grafo completo orientado, onde $N=\{0, \ldots, n\}$ representa o conjunto de nós, e $A=\{(i, j) \mid i \in$ $N \wedge j \in N \wedge i \neq j\}$ o conjunto de arcos que interligam os pontos saindo de $i$ com destino a $j, c_{i j}$ o custo do arco $(i, j)$. Procura-se a rota de custo mínimo, sendo que a variável binária $x_{i j}$ possui valor 1 se, e somente se, o arco $(i, j)$ for utilizado.

$$
\min z=\sum_{i \in N} \sum_{j \in N} c_{i j} x_{i j}
$$

sujeito a

$$
\begin{array}{ll}
\sum_{i \in N} x_{i j}=1 & \forall i \in N \\
\sum_{j \in N} x_{i j}=1 & \forall j \in N \\
x_{i j} \in\{0,1\} & \forall i, j \in N
\end{array}
$$

A Função Objetivo (2-1) minimiza o custo de transporte. As Restrições (2-2) e (2-3) obrigam que cada local seja visitado somente uma vez. A Restrição 
(2-4) atribui a característica binária de $x_{i j}$.

Observa-se que a formulação acima proposta pode resultar numa solução em que os pontos não estão conectados, formando-se os subciclos. Conforme Pataki (2003), as principais formas de eliminá-los são através das Restrições de Eliminação de Subciclos, conhecida como Subtour Elimination Constraints (SEC); e do método de Miller, Tucker e Zemlim (MTZ), que serão brevemente abordados nesta seção.

\subsection{1}

\section{Restrição de Eliminação de Subciclos}

As SEC foram inicialmente desenvolvidas por Dantzig et al. (1954), cuja proposta foi de limitar a quantidade de arcos associados a cada subconjunto $S \subset N$. Para tanto, basta incluir na formulação inicial as Restrições (2-5).

$$
\sum_{i \in S} \sum_{j \in S} x_{i j} \leq|S|-1
$$

A Figura 2.3 ilustra a eficácia das SEC em um subconjunto de 5 vértices de um grafo de 10 pontos.
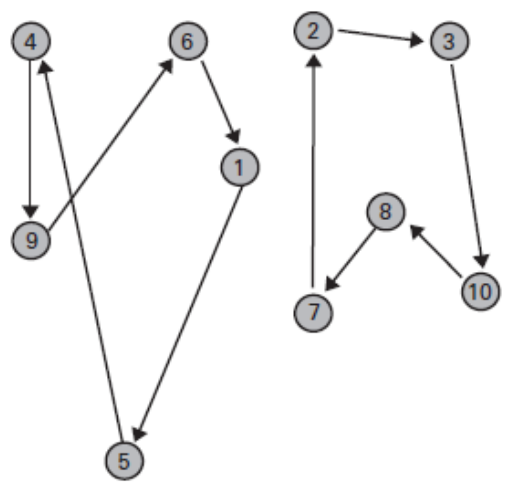

$$
\sum_{i, j} x_{i j}=5 \quad \sum_{i, j} x_{i j}=5
$$

(a) solução ilegal
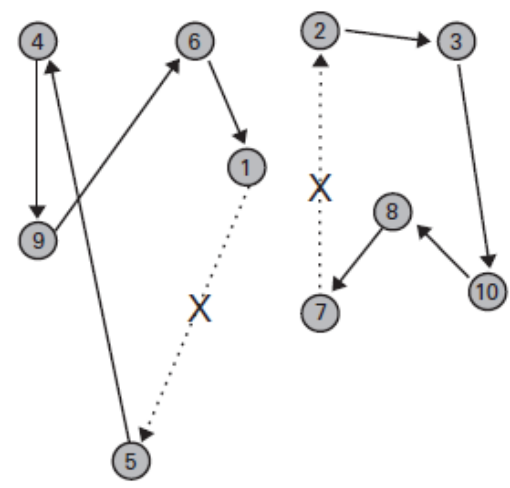

$$
\sum_{i, j} x_{i j} \leq|5|-1 \leq 4
$$

(b) restrições associadas

Figura 2.3: Atuação do SEC.

Fonte: Goldbarg (2005)

De acordo com Drexl (2013), uma desvantagem das SEC é que a quantidade de restrições cresce exponencialmente com a quantidade de demandas do problema. Por outro lado, esse número pode ser reduzido, pois nem todos os subconjuntos precisam ser incluídos na formulação inicial. Para tanto, eles são 
gerados conforme a necessidade por um algoritmo específico de separação de SEC violadas (Pataki 2003).

\subsection{2}

\section{Miller-Tucker-Zemlim}

O método que ficou conhecido na literatura como MTZ, foi criado por Miller et al. (1960), como uma alternativa mais eficiente aos demais modelos da época, em termos de generalidade, número de variáveis e de restrições. O propósito da formulação é a criação de uma variável $u_{i}$ que indicará a ordem de atendimento do local.

Para tal, basta incluir na formulação inicial do TSP as Restrições (2-6) e (2-7). Considera-se que o local 1 é o depósito (ou a origem e o fim da rota) e $p$ é a quantidade de locais.

$$
\begin{array}{ll}
u_{i}-u_{j}+p x_{i j} \leq p-1 & \forall i \in N, j \in N, i \neq j, i \neq 1, j \neq 1 \\
0 \leq u_{i} \leq p & \forall i \in N
\end{array}
$$

Nessa formulação, observa-se que, se o arco $(i, j)$ for integrante da solução, $x_{i j}=1$; então $u_{i}-u_{j} \leq-1$. Sendo assim, a Restrição MTZ obriga que $u_{j}$ possua valor superior à $u_{i}$ em pelo menos 1 , tornando a solução ordenada e, consequentemente, conectada. Segundo Pataki (2003), além do tamanho menor que as SEC, outra grande vantagem da MTZ é que, caso seja preferível atribuir locais a serem atendidos prioritariamente, basta incluir um termo $-\alpha u_{i}$ com alguns $\alpha \geq 0$ no objetivo.

Posteriormente, Desrochers e Laporte (1991) adaptaram a MTZ, para a aplicação no VRP com janelas de tempo. Além de cumprir seu papel principal (a eliminação de subciclos e a ordem de atendimento), o método de Desrochers e Laporte (1991) indica o limite de tempo em que a demanda é atingida, sendo fundamental para os casos em que é necessário se cumprir limites de chegada e de saída do veículo em cada ponto.

\section{4}

\section{Algoritmos de solução do VRP}

A representação adequada de um sistema real por meio de modelos matemáticos possui grandes desafios, já que nem todos os fenômenos podem ser traduzidos através de lógica ou por variáveis de decisão (Goldbarg 2005). Outrossim, a quantidade de variáveis e de restrições podem tornar o modelo demasiadamente complexo e com tempo de resolução de otimização muito 
superior ao desejado. Nestes casos, alternativas que se tornam adequadas são a heurística e a meta-heurística, que são mecanismos de busca de soluções viáveis, mas sem garantia de otimalidade.

Nesse contexto, segundo Laporte (2009) e Braekers et al. (2016), para o VRP, os melhores algoritmos de resolução seriam as heurísticas e as metaheurísticas, visto a grande gama de destinos existentes na maioria dos problemas reais, levando em consideração que é desejável se obter soluções rápidas.

Antigamente, os algoritmos exatos conseguiam solucionar problemas limitados a 30 destinos (Laporte e Norbert 1987). Contudo, a evolução dos modelos tornou possível ampliar as dimensões, como o elaborado por Pecin et al. (2017), que consegue atender até 199 clientes. A despeito da diversidade de restrições adicionais do HALRPPA, é esperado que o algoritmo exato resolva satisfatoriamente uma quantidade pequena de clientes (até 25 destinos). Além disso, segundo Goldbarg (2005), a heurística é uma alternativa razoável apenas quando não há a possibilidade de desenvolver o modelo exato, ou quando a otimização não é tão importante quanto o tempo de resolução.

\subsection{1 \\ Heurísticas e Meta-heurísticas}

As heurísticas são métodos de obtenção de soluções de boa qualidade em um tempo mais rápido em relação aos modelos de otimização. Conforme Arroyo (2002), as heurísticas podem ser divididas em três classes: i) as contrutivas; ii) a Busca Local; e iii) meta-heurísticas, que são os métodos que possuem estruturas estrategicamente montadas para adquirir soluções ainda mais precisas do que as heurísticas clássicas. As meta-heurísticas mais conhecidas na literatura de VRP são a Busca Tabu, Simulated Annealing, Greedy Randomized Adaptive Search Procedure (GRASP), algoritmo genético e Iterated Local Search (ILS). Contudo, as heurísticas mais recentes utilizadas no transporte aeroterrestre foram as baseadas na Relaxação Lagrangeana (RL) e o Local Branching.

A Relaxação Lagrangeana (RL) é uma técnica de solução de modelos complexos que consiste, superficialmente, na relaxação de um conjunto de restrições que ao serem violadas acarretam em penalizações (proporcionais ao tamanho da violação) na função objetivo. Assim, o método resolve o problema de forma iterativa, até zerar as penalizações, encontrando uma solução. A partir de então, é possível decompor o problema original em subproblemas de resolução mais fáceis (Ahuja et al. 1993).

Nos trabalhos de Huang e Chi (2007), Chang (2008), Li et al. (2012) e Huang et al. (2020), o algoritmo heurístico foi baseado na RL, através dos seguintes passos: i) determinar as configurações iniciais; ii) resolver os 
subproblemas lagrangeanos; iii) encontrar a solução viável; e iv) checar o critério de interrupção e atualizar os multiplicadores lagrangeanos.

O Local Branching, utilizado por Li et al. (2012), é uma estratégia de solução que aperfeiçoa as técnicas heurísticas a qual se baseia em uma exploração mais apurada do espaço de soluções (Fischetti e Lodi 2003).

\section{4 .2 \\ Métodos Exatos}

De acordo com Goldbarg (2005), os algoritmos exatos traduzem a busca pela perfeição, ou seja, pela melhor solução possível para um dado um problema. A desvantagem é que, para os problemas NP-difíceis como é a maioria dos casos de VRP, o horizonte de possíveis soluções cresce exponencialmente à quantidade de locais e de restrições. Por esse motivo, são raros os trabalhos mais recentes em transporte intermodal que utilizam métodos exatos, como a Programação Dinâmica (PD) e o Branch-and-Bound (B\&B).

A PD é uma técnica de otimização realizada através de um processo de decisões em etapas sequenciais (Goldbarg 2005). Um tipo de PD é o algoritmo de Rótulos, conhecido como Label Setting algorithm (LS), que consiste na atribuição de rótulos em cada nó do grafo, composto por um par (peso, função objetivo). Os passos do LS são: i) determinar as configurações iniciais; ii) selecionar o rótulo que será estendido (se todos os rótulos estiverem marcados, o algoritmo encerra); iii) estender o rótulo; iv) reconfigurar os rótulos e retorna ao passo ii (Cho et al. 2012).

Segundo Korte e Vygen (2000), o B\&B consiste na busca da solução ótima dentre todo o universo de soluções, sem que haja a necessidade de calculálas uma a uma, através de cortes ou podas. Para isso, são necessárias duas etapas: i) a ramificação das soluções conhecidas (branch) em dois ou mais subconjuntos não vazios; e ii) para cada nova solução encontrada, as podas (bound) são realizadas por inviabilidade (a introdução da restrição torna o problema infactível), otimalidade (quando se encontra a solução inteira, mas não necessariamente a ótima) ou por limite (quando o valor da relaxação linear é pior que a solução da ramificação).

Embora nenhum trabalho recente em transporte intermodal tenha utilizado unicamente o B\&B, Leung et al. (2009) desenvolveram uma heurística elaborada a partir dessa técnica para solucionar um Problema de Consolidação de Cargas Aéreas. Além disso, os resolvedores modernos, como o CPLEX e o Gurobi, utilizam o B\&B com a implementação de técnicas avançadas de cortes para tornar a solução mais rápida (Ducharme 2012). 


\section{3 \\ Metodologia}

Neste capítulo serão apresentados os métodos para a formulação do modelo. A Seção 3.1 apresenta os aspectos do modelo que não são contemplados no clássico VRP, bem como a definição das variáveis e dos parâmetros. As demais seções definem as premissas e a formulação matemática.

\section{1}

\section{Descrição do Problema}

\subsection{1}

\section{Linhas Aéreas}

As linhas aéreas são rotas abertas, portanto, formadas por arcos no grafo. Cada arco possui custo e capacidade de acordo com a especificação da aeronave que realiza o trecho. A Figura 3.1 retrata um exemplo fictício de rotas aéreas com as imagens das aeronaves extraídas de BRASIL (2020). Neste exemplo há três LAP: a LAP1 que cumpre a rota $(1,2)$, com a aeronave C-130; a LAP2 que realiza a $(1,5,6)$, com a C-105; e a LAP3 que percorre $(5,4,3,2)$, com a C-99. Portanto, a capacidade do arco $(5,4)$ é a capacidade da aeronave C-99. Os custos de transporte aéreo também serão atribuídos a cada arco, de acordo com o consumo da aeronave e o tempo de deslocamento entre os pontos.

\subsection{2}

\section{Transbordo}

Conforme comentado na Seção 2.2, a abordagem de Gavish e Graves (1982) foi utilizada neste trabalho para modelar o transbordo de carga, que ocorre quando uma parte da rota é atendida por um veículo e o restante por outro. Isso ocorre porque as linhas aéreas são abertas e, consequentemente, só podem coletar e entregar as cargas nos locais que são pertencentes às suas rotas. Outrossim, como a frota é heterogênea tanto no custo como na capacidade, o modelo pode decidir por transportar cargas inferiores por caminhões menores (custo e capacidade inferior) a um determinado ponto, e outro caminhão maior consolidar as cargas e levá-las para o destino. A Figura 3.2 é uma imagem, retratada pelo G1 (2014), que demonstra o transbordo de uma carga de cartas 


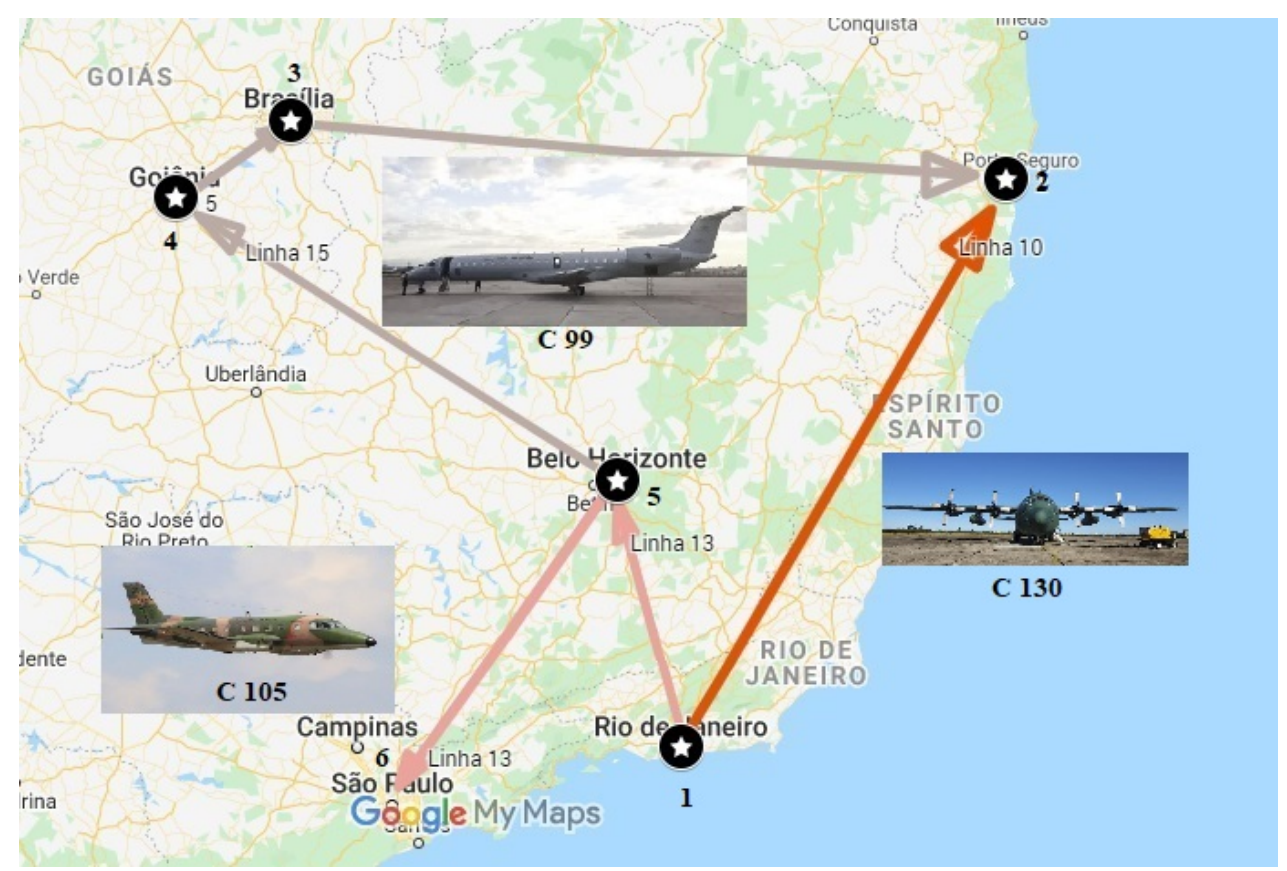

Figura 3.1: Exemplo de linhas aéreas

Fonte: O Autor

trazidas em um avião cargueiro, para distribuição em um local remoto. Na Figura 1.4, há o transbordo no ponto 6, já que as demandas dos pontos 7 e 8 são descarregadas no ponto 6 e a aeronave realiza as entregas percorrendo a linha verde.

\subsection{3}

\section{Descrição do Modelo}

Seja $G=(N, A)$ um grafo completo orientado, onde $N=\{0, \ldots, n\}$, sendo que o vértice 0 corresponde ao depósito e os nós em $N^{+}=\{1, \ldots, n\}$ correspondem aos clientes; e $A=\{(i, j) \mid i \in N \wedge j \in N \wedge i \neq j\}$ o conjunto de arcos que interligam os pontos saindo de $i$ com destino a $j$. A cada cliente $j \in N^{+}$é atribuído um volume $V o l_{j}$ e um peso $w_{j}$ que representam as características das entregas a serem realizadas.

Em relação aos veículos, define-se $K=\{1, \ldots, k\}$ como o conjunto de veículos, em que a constante $a=1$ representa todos os deslocamentos aéreos, $K T=\{2, \ldots, k\}$ ilustram os caminhões. Além disso, há cargas que exigem determinadas categorias de veículos, tornando necessária a criação de restrições de elegibilidade, para tanto, definem-se os subconjuntos: $N T \subseteq N$ que representa os locais que podem ser atendidos por caminhões; $N 0 \subseteq N$ e $N I \subseteq N$ que retratam os dois tipos de demandas que só podem atendidas pelas classes de veículos $K 0 \subseteq K T$ e $K I \subseteq K T$, respectivamente. Um custo variável $C_{k}$, é associado a cada veículo que, ao multiplicá-lo por $d_{i j}$ que é a distância de $i$ 


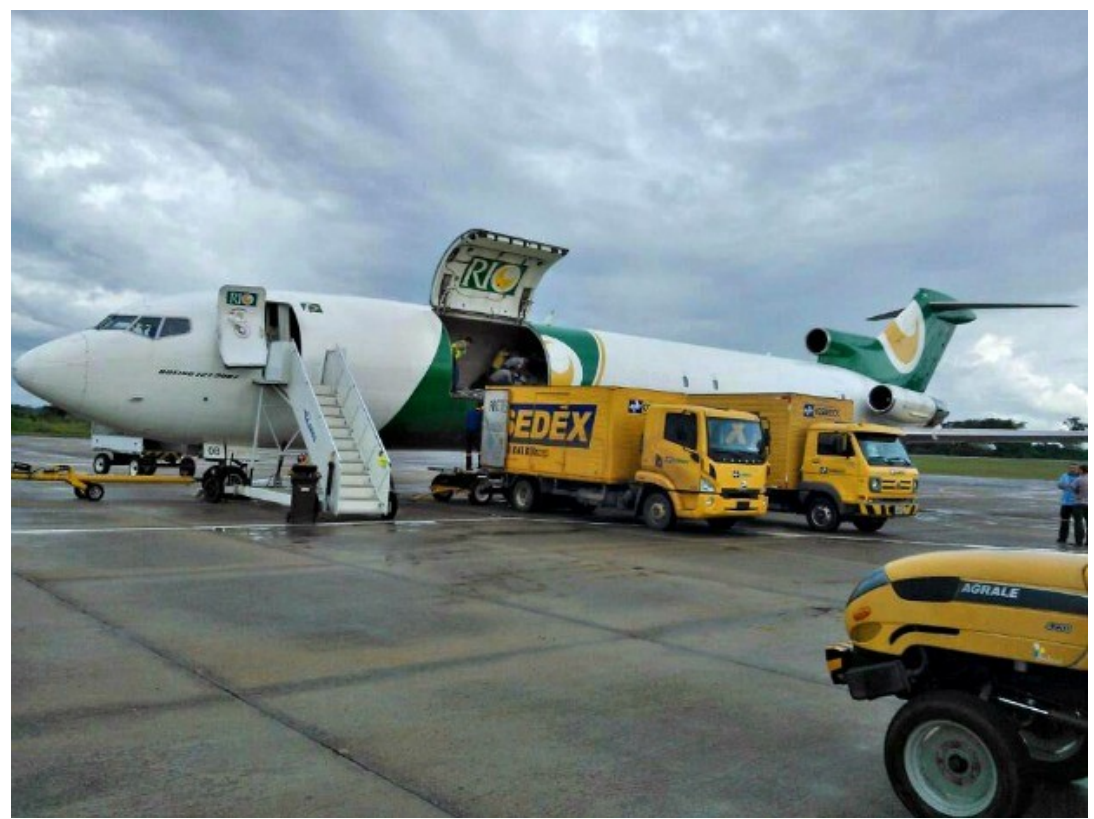

Figura 3.2: Transbordo entre uma aeronave e um caminhão

Fonte: G1 (2014)

para $j$, retornará o custo de transporte do veículo $k$, para ir de $i$ para $j$. Cada caminhão possui um limite máximo de volume total a ser transportado $C A P_{k}$ e de tempo de ciclo máximo $T C$. $T_{i j}$ é o tempo de deslocamento de $i$ para $j$. Finalmente, $x_{i j}^{k}$ é a variável binária de decisão do veículo $k$ deslocar-se de $i$ para $j ; f_{i j}^{k p}$ é a variável de fluxo de commodity de movimento no arco $(i, j) \in$ $A$, no veículo $k$, transportando a totalidade da demanda do local $p \in N^{+}$; e $t_{j k}$ é a variável inteira associada ao tempo de chegada do veículo $k$ em $j$.

Já para o transporte aéreo, primeiramente será proposto o subgrafo $G^{\prime}=$ $\left(N^{\prime}, A^{\prime}\right)$ que contém apenas os arcos que fazem parte das LAP. A cada arco $(i, j) \in A^{\prime}$ é associado $C A_{i j}$, que denomina o custo aéreo de deslocamento de $i$ para $j$ e uma capacidade máxima de peso $W A_{i j}$ para o transporte de $i$ para $j$. Em seguida, define-se o veículo $a \in K$, o qual será associado aos arcos de $A^{\prime}$ e representará todas as aeronaves.

\section{2}

\section{Premissas}

Assim como nos modelos básicos de VRP, cada cliente é atendido por exatamente um caminhão / aeronave, enquanto cada caminhão / aeronave pode servir vários clientes. Além disso, cada caminhão inicia no depósito, entrega mercadorias a um subconjunto de clientes e retorna ao depósito. Em contrapartida, as LAP são abertas, portanto, não possuem necessariamente origem e fim no depósito. 
Em relação ao custo de transporte aéreo, via de regra, ao avaliar tão somente os custos do transporte, o modal aéreo é exorbitantemente mais dispendioso do que o terrestre. Contudo, as aeronaves podem reservar parte de sua capacidade máxima de carga para realizar o transporte de passageiros. Consequentemente, torna-se necessário atribuir um Fator de Custo (FC) que ilustra a porcentagem de relevância do transporte de cargas em relação ao de passageiros. Assim sendo, quando o $F C=100 \%$, significa que a aeronave foi deslocada exclusivamente para realizar a entrega de carga, ou seja, não há passageiros à bordo; ao passo que $F C=0 \%$ pode-se inferir que a aeronave está com a sua capacidade quase que completamente comprometida por motivos alheios à entrega do pedido.

\section{3}

\section{Formulação do Modelo}

$$
\min z=\sum_{i \in N} \sum_{j \in N}\left(C A_{i j} F C x_{i j}^{a}+\sum_{k \in K T} C_{k} d_{i j} x_{i j}^{k}\right)
$$

sujeito a

$$
\begin{array}{ll}
\sum_{p \in N^{+}} V_{o} f_{p}^{p k} \leq C A P_{k} x_{i j}^{k} & \forall i, j \in N T, k \in K T \\
\sum_{p \in N^{+}} w_{p} f_{i j}^{p a} \leq W A_{i j} x_{i j}^{a} & \forall(i, j) \in A^{\prime}
\end{array}
$$

$\sum_{i \in N} \sum_{k \in K}\left(f_{i j}^{p k}-f_{j i}^{p k}\right)=\left\{\begin{array}{rl}-1, & \text { se } j=0, \\ 0, & \text { c.c., } \\ 1, & \text { se } j=p .\end{array} \quad \forall j \in N, p \in N^{+}\right.$

$$
\begin{array}{ll}
\sum_{i \in N T}\left(x_{i j}^{k}-x_{j i}^{k}\right)=0 & \forall j \in N T, k \in K T \\
\sum_{j \in N T} x_{0 j}^{k} \leq 1 & \forall k \in K T \\
t_{j k} \geq t_{i k}+T_{i j}-T C\left(1-x_{i j}^{k}\right) & \forall i, j \in N T, k \in K T \\
\sum_{j \in N T} \sum_{k \in K I}\left(x_{i j}^{k}+x_{j i}^{k}\right)=0 & \forall i \in N 0 \\
\sum_{j \in N T} \sum_{k \in K 0}\left(x_{i j}^{k}+x_{j i}^{k}\right)=0 & \forall i \in N I \\
0 \leq t_{j k} \leq T C & \forall i \in N, k \in K T \\
x_{i j}^{k} \in\{0,1\} & \forall i, j \in N, k \in K \\
f_{i j}^{p k} \in\{0,1\} & \forall i, j \in N, p \in N^{+}, k \in K
\end{array}
$$

A Função Objetivo (3-1) minimiza os custos de transporte aéreos e 
terrestres. As Restrições (3-2) e (3-3) são, respectivamente, as restrições de capacidade terrestre e aérea. As Restrições de (3-4) a (3-6) são as restrições de conservação do fluxo. A Restrição (3-4) conserva o fluxo do pedido $p$ entre $i$ e $j$, permitindo o transbordo entre os veículos; a Restrição (3-5) conserva o fluxo de veículos nas rotas terrestres; e a Restrição (3-6) impede que um caminhão realize mais de uma rota. A Restrição (3-7) é a MTZ de impedimento da formação de subciclos. As Restrições (3-8) e (3-9) definem a elegibilidade entre as cargas e veículos terrestres. As Restrições (3-10) associam o $t_{j k}$ ao tempo de ciclo, sendo que, as Restrições (3-7) e (3-10), conjuntamente, limitam o TC nas rotas terrestres. Por fim, as Restrições (3-11) e (3-12) aplicam a característica binária de $x_{i j}^{k}$ e $f_{i j}^{p k}$. 


\section{4}

\section{Estudo de caso}

Neste capítulo serão apresentadas todas as informações extraídas da pesquisa de campo no órgão em estudo. Primeiramente será passada uma breve descrição da empresa, depois as características das atividades que não serão contempladas pelo modelo e, no final do capítulo, a organização dos dados para a implementação do modelo.

\section{1}

\section{Descrição do Caso}

O órgão em estudo, apelidado de Centro Logístico (CL), possui como missão institucional realizar o transporte de cargas para todo o território nacional, tendo à sua disposição uma frota própria de caminhões e de aeronaves. O CL possui um depósito central e 25 clientes espalhados pelo território nacional. Na Figura 4.1 consta o mapa contendo o CL, representado pelo ponto 1 e todos os 25 possíveis destinos (2 a 26).

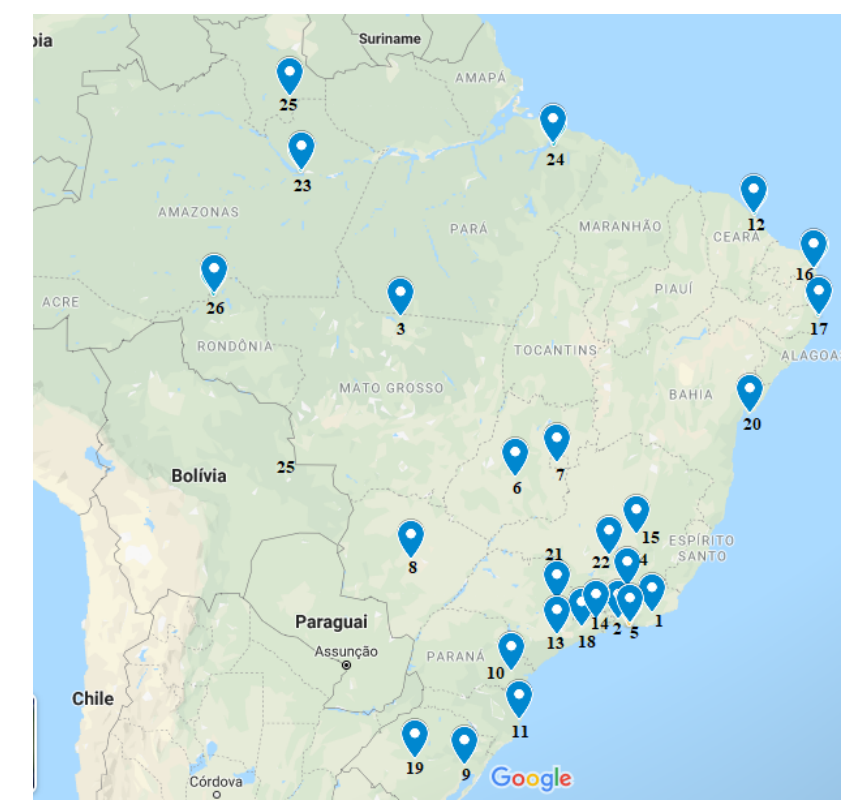

Figura 4.1: Mapa completo.

Fonte: O autor

Existem 10 LAP que as aeronaves percorrem quinzenalmente. Nessas rotas, estão incluídos os locais remotos em que os caminhões não chegam (pontos 
23, 24, 25 e 26). Há cinco tipos de aeronaves, sendo que cada LAP é atendida exclusivamente por uma delas, em outras palavras, não há a possibilidade de intercambiar os tipos de aeronaves entre as LAP. A Figura 4.2 ilustra o mapa completo de LAP que o órgão possui e na Tabela 4.1 consta a descrição de suas rotas e as aeronaves que as executam. Sempre que há uma demanda que pode ser atendida por uma aeronave, o CL procura atendê-la, caso não ultrapasse o limite de peso da aeronave. Alternativamente, para o atendimento emergencial ou estratégico, o CL utiliza seus caminhões para o transporte de cargas. A frota de caminhões e aeronaves são heterogêneas, portanto, possuem capacidades e custos distintos. Inclusive, um dos veículos é da categoria de caminhão prancha que é destinada unicamente para o transporte de cargas de grande porte e indivisíveis, ou seja, não podem ser fracionadas em volumes menores, como exemplo: máquinas, automóveis, aeronaves, dragas, etc.

Tabela 4.1: Descrição das LAP.

\begin{tabular}{ccc}
\hline LAP & Rota & Aeronave \\
\hline 1 & $(1,11,9,19)$ & 2 \\
2 & $(1,7)$ & 1 \\
3 & $(7,20,16)$ & 3 \\
4 & $(7,3)$ & 4 \\
5 & $(7,6,8)$ & 4 \\
6 & $(7,22,21)$ & 5 \\
7 & $(7,23)$ & 3 \\
8 & $(23,24)$ & 3 \\
9 & $(23,25)$ & 3 \\
10 & $(23,26)$ & 3 \\
\hline
\end{tabular}

Além disso, é importante destacar que existe a possibilidade de uma aeronave ser deslocada para cumprir um trecho que não faz parte das LAP. Essas rotas, chamadas de rotas extraordinárias (RE), não compõem o planejamento de transporte do órgão, muito em virtude de que a informação sobre essas rotas não necessariamente chegam ao órgão no período de preparação da programação dos trajetos. 


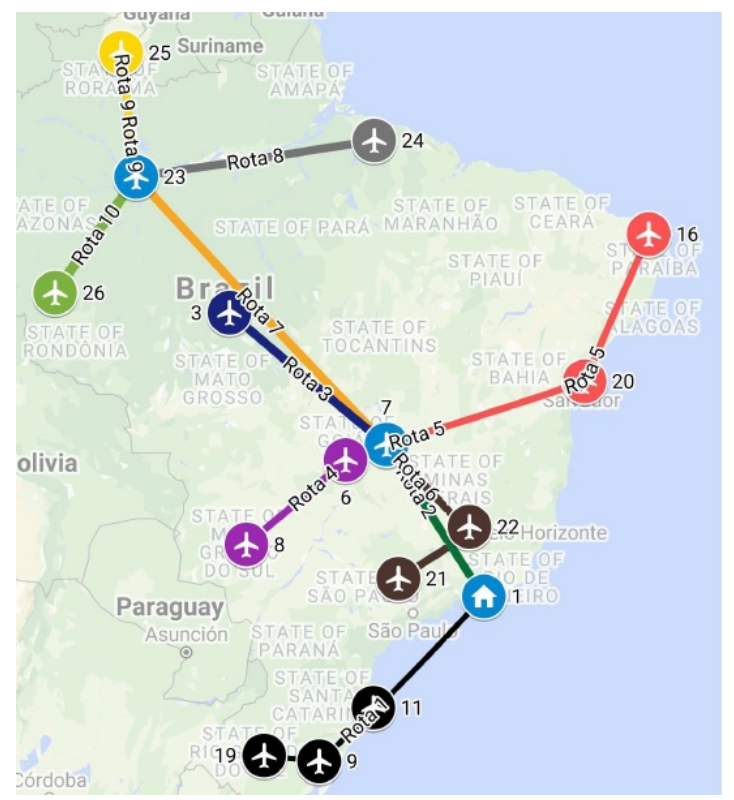

Figura 4.2: Mapa das LAP.

Fonte: O autor.

\section{2}

Simplificações

Algumas restrições observadas no caso não fizeram parte deste estudo para que o modelo não se tornasse demasiadamente complexo, de tal forma que a resolução não fosse obtida em tempo aceitável. A primeira simplificação é relativa ao horizonte de planejamento e o $T C$, pois o modelo não contempla as pausas para descanso dos motoristas. O CL possui um prazo de entrega de quinze dias, todavia, uma forma de compensar o limite de jornada de trabalho foi na adoção de um $T C$ de apenas cinco dias. Essa sintetização pode ser considerada coerente, já que o prazo de entrega é reduzido na mesma proporção (um terço) da relação entre o tempo de uma jornada de trabalho (oito horas) à quantidade total de horas em um dia (24 horas). Além disso, cabe destacar que o $T C$ das aeronaves foram ignoradas, visto que o transporte aéreo é extremamente rápido (no máximo 4h para as distâncias mais longas para viagens nacionais), sendo irrelevante para o cômputo do total dos $T C$.

A segunda é relacionada às restrições de capacidade. O limite de peso máximo dos caminhões possuem baixa probabilidade de ultrapassagem, portanto, a restrição de capacidade dos veículos terrestres se resume exclusivamente ao volume das cargas. No caso das aeronaves a situação é inversa, já que o volume não é um fator limitante como ocorre com o peso. Contudo, há a possibilidade das dimensões das cargas ultrapassarem a largura do caminhão ou da porta do avião, porém essas restrições de dimensões não foram contempladas no modelo. 
Ainda comentando sobre as cargas aéreas, existem categorias de materiais cujo transporte aéreo é vedado, contudo, como a regulamentação é extremamente complexa, haveria a necessidade de criação de uma série de restrições que poderiam inviabilizar o modelo.

A terceira simplificação, que também foi feita para não inviabilizar o tempo de solução, é a existência da oferta de produtos em outros pontos além do depósito central. Dessa forma, haveria a necessidade de realização de entregas e coletas nos destinos (pickup-and-delivery).

A última se refere ao cálculo do $F C$. Conforme comentado na Seção 3.2 , há a necessidade de se deflacionar o $C A_{i j}$ através de um $F C$, por conta da possibilidade de se realizar múltiplas tarefas com uma aeronave. Nesse sentido, as aeronaves que atendem o CL cumprem não apenas as atividades de transporte de carga e de passageiros, mas também, atividades de treinamento, patrulha aérea e inspeção de voo. Além disso, ressalta-se que o CL exerce um papel social preponderante em regiões remotas que não possuem acesso por veículos terrestres, realizando a entrega de alimentos, medicamentos e outros materiais para as comunidades carentes. Então, conclui-se que o transporte de cargas para o CL pode ser considerado uma atividade subsidiária na realização do planejamento das operações aéreas.

Contudo, o órgão não possui uma metodologia para estimar o $F C$ e, por esse motivo, atribuiu-se três valores: $0 \%, 10 \%$ e 20\%. Em cada período estudado, realizou-se as iterações para cada um dos $F C$ com o objetivo de se estudar a sensibilidade do modelo nesse aspecto. Além da questão da métrica de cálculo, o $F C$ não necessariamente precisa ser representado por um valor fixo de deflação aplicado em todas as rotas, mas também, pode ser definido um $F C$ para cada linha aérea ou partes dela.

\section{3}

\section{Coleta e Tratamento dos Dados}

A pesquisa de campo contemplou a coleta e a análise dos dados relativos ao ano de 2019. As informações foram organizadas em quatro grupos: o primeiro e o segundo são relativos às características da frota aérea e terrestre, respectivamente; o terceiro diz respeito ao levantamento das informações das demandas de três períodos; e por último, as rotas efetivamente realizadas (RER) pelo órgão. 


\subsection{1}

\section{Custos Aéreos}

O $C A_{i j}$ foi calculado da seguinte forma: i) obtém-se o custo aéreo total (CAT) através da soma dos seguintes custos: manutenção e modernização, combustíveis e lubrificantes, manutenção de simuladores e aquisição de aeronaves; ii) afere-se o custo da hora de voo (CHV) a partir da divisão do $C A T$ pelas horas de voo (HV) que cada aeronave realizou; e iii) multiplica-se o $C H V$ pelo tempo, em horas, de deslocamento aéreo (tA) de $i$ para $j$. A Equação (4-1) ilustra o cálculo do custo aéreo.

$$
C A_{i j}=\frac{C A T t A_{i j}}{H V}
$$

Em relação à frota, os tipos de aeronaves possuem custos e capacidades distintas. A Tabela 4.2 retrata as especificações das aeronaves. Na coluna 2 consta o $C H V$, na próxima coluna o limite de peso $W A$ e, na última coluna, estão as LAP que cada tipo de avião realiza.

Tabela 4.2: Especificações das aeronaves.

\begin{tabular}{crrr}
\hline Aeronave & \multicolumn{1}{c}{ CHV } & WA & LAP \\
\hline 1 & $17.034,35$ & 3000 & 2 \\
2 & $4.887,59$ & 1700 & 1 e 6 \\
3 & $43.908,29$ & 24163 & $3,7,8,9$ e 10 \\
4 & $17.404,25$ & 9200 & 4 e 5 \\
\hline
\end{tabular}

Ademais, para o cálculo do $t A_{i j}$ de cada trecho da LAP, aferiu-se as distâncias aéreas entre os pontos e considerou-se uma velocidade de $550 \mathrm{~km} / \mathrm{h}$, a média atingida pelas aeronaves em estudo. Esses valores foram obtidos através da inserção das coordenadas dos locais (extraídas do Bing Maps) no VRP Spreadsheet Solver, uma extensão do Microsoft Excel, que foi desenvolvido por Erdoğan (2017) para solucionar diversas extensões do VRP. Com a posse do $C H V$ e $\operatorname{dos} t A_{i j}$, confecciona-se a matriz de $C A_{i j}$.

\subsection{2}

\section{Custos Terrestres}

Os custos terrestres $C_{k}$ foram considerados apenas como custos variáveis, em função da distância percorrida, que serão calculados da seguinte forma: i) afere-se o consumo de cada caminhão cons $_{k}$, em quilômetros por litro; ii) estima-se o preço médio do diesel $v_{\text {diesel }}$, por litro; e iii) somam-se todos os demais custos diversos $C D$ (que englobam a arla, manutenção, rastreadores e documentação) e divide-se pela distância percorrida, em quilômetros, de todos os caminhões. Pode-se resumir a fórmula do custo terrestre conforme a Equação $(4-2)$. 


$$
C_{k}=\frac{v_{\text {diesel }}}{\text { cons }_{k}}+C D
$$

A frota terrestre é composta por 11 caminhões que possuem três categorias: i) veículos de capacidade de transporte de grandes volumes, alto consumo de combustível e que transporta cargas divisíveis; ii) veículos de transporte de cargas divisíveis com capacidade e consumo inferiores; e iii) caminhões do tipo prancha que transportam apenas cargas indivisíveis. A Tabela 4.3 contém as características da frota terrestre, com as informações do período em estudo, cujo valor médio de $v_{\text {diesel }}$ foi de 4,5 reais/L; e o valor do $C D$ foi 1,56 reais/Km. A primeira linha representa os índices de $k$, sendo que o índice 1 está reservado para as aeronaves; em seguida estão as categorias (Tipo) dos veículos terrestres; na terceira e na quarta linha estão, respectivamente, as capacidades $C A P_{k}$ e os valores de Cons $_{k}$ de cada caminhão; e na última linha está o valor de $C_{k}$.

Tabela 4.3: Especificações dos caminhões.

\begin{tabular}{crrrrrr}
\hline$k$ & 1 & 2 & 3 & 4 & 5 & 6 \\
\hline Tipo & $\mathrm{a}$ & 1 & 3 & 1 & 1 & 1 \\
CAP & - & 63,00 & 118,65 & 85,00 & 85,00 & 55,00 \\
Cons $_{k}$ & - & 3,0 & 1,7 & 3,9 & 3,9 & 4,1 \\
$C_{k}$ & - & 3,06 & 4,21 & 2,71 & 2,71 & 2,66 \\
\hline$k$ & 7 & 8 & 9 & 10 & 11 & 12 \\
\hline Tipo & 1 & 2 & 2 & 2 & 2 & 1 \\
CAP & 63,79 & 27,00 & 48,29 & 30,92 & 36,65 & 65,00 \\
Cons $_{k}$ & 4,0 & 4,4 & 4,2 & 5,0 & 5,0 & 2,9 \\
$C_{k}$ & 2,69 & 2,58 & 2,63 & 2,46 & 2,46 & 3,11 \\
\hline
\end{tabular}

Assim como ocorreu com o modal aéreo, utilizou-se o VRP Spreadsheet Solver de Erdoğan (2017) e o Bing Maps para confeccionar a matriz de $d_{i j}$. Configurou-se o método de cômputo da distância para Bing Maps driving distances $(\mathrm{km})$. Além disso, como a velocidade média combinada (rodoviária e trajeto urbano) atingida pelos caminhões foi de $60 \mathrm{~km} / \mathrm{h}$, o $T_{i j}$ será calculado como $d_{i j} / 60$.

\subsection{3}

\section{Demanda}

A demanda foi obtida através de um sistema de gerenciamento de movimentação de cargas que subsidia o gestor de operações do CL para a elaboração do planejamento das rotas. Os clientes registram a necessidade de recebimento de materiais oriundos do CL, informando o volume, o peso, a urgência e uma lista detalhada com a descrição dos produtos. 
As informações sobre as demandas nos três períodos estão listadas na Tabela 4.4. Na primeira coluna estão os locais de entrega e, nas demais, constam o peso e o volume para cada período.

Tabela 4.4: Especificações das demandas.

\begin{tabular}{|c|c|c|c|c|c|c|}
\hline \multirow[b]{2}{*}{ Local } & \multicolumn{2}{|c|}{ Período 1} & \multicolumn{2}{|c|}{ Período 2} & \multicolumn{2}{|c|}{ Período 3} \\
\hline & Peso & Volume & Peso & Volume & Peso & Volume \\
\hline 2 & 46,0 & 0,327 & 20,0 & 0,024 & 1819,0 & 7,281 \\
\hline 3 & 1590,0 & 8,306 & - & - & - & - \\
\hline 4 & 150,4 & 0,940 & - & - & - & - \\
\hline 5 & 191,0 & 0,875 & - & - & 67,0 & 0,757 \\
\hline 6 & 67,0 & 0,453 & 1,0 & 0,001 & 1725,8 & 4,278 \\
\hline 7 & 273,94 & 0,730 & 321,0 & 0,604 & 2502,7 & 15,208 \\
\hline 8 & 199,1 & 0,979 & - & - & 19,5 & 0,204 \\
\hline 9 & 991,1 & 9,769 & 38,0 & 0,091 & 200,8 & 1,613 \\
\hline 10 & 176,9 & 0,769 & - & - & 2,0 & 0,020 \\
\hline 11 & 307,8 & 0,549 & - & - & 93,0 & 0,618 \\
\hline 12 & 5,0 & 0,050 & - & - & 46,0 & 0,393 \\
\hline 13 & 1707,9 & 11,378 & 1561,0 & 5,661 & 2789,4 & 12,196 \\
\hline 14 & 16,0 & 0,082 & - & - & 1,0 & 0,031 \\
\hline 15 & - & - & - & - & - & - \\
\hline 16 & 569,4 & 1,810 & - & - & 328,5 & 1,456 \\
\hline 17 & 742,0 & 6,722 & 467,6 & 1,936 & 16,0 & 0,150 \\
\hline 18 & 299,7 & 1,261 & & & 5,0 & 0,141 \\
\hline 19 & 262,5 & 1,371 & 5,2 & 0,012 & 3,2 & 0,030 \\
\hline 20 & 1,5 & 0,029 & 1,5 & 0,029 & 10,0 & 0,141 \\
\hline 21 & - & - & - & - & 1,0 & 0,031 \\
\hline 22 & 2974,3 & 15,465 & 806,5 & 2,080 & 407,2 & 2,601 \\
\hline 23 & - & - & 240,8 & 0,326 & 666,9 & 2,053 \\
\hline 24 & - & - & - & - & 60,9 & 0,563 \\
\hline 25 & - & - & - & - & 4065,0 & 29,289 \\
\hline 26 & - & - & 21,0 & 0,022 & 2026,9 & 7,095 \\
\hline
\end{tabular}

\subsection{4}

\section{Rotas Efetivamente Realizadas}

O levantamento das RER dos três períodos foi extraído do sistema de gerenciamento do órgão, que emite relatórios sobre a movimentação das demandas. Além disso, foi realizado um cruzamento desses dados com o registro diário de saída de veículos, um documento em que o órgão lança as placas dos veículos que saíram em viagem, bem como as rotas que foram planejadas.

Embora não haja relatórios de rastreabilidade para verificar se houve desvios de rotas por motivos diversos como, por exemplo: interdição rodovias e mudança do planejamento por fatos extraordinários. Considerou-se que todas as rotas planejadas foram realmente cumpridas. A Tabela 4.5 apresenta as RER 
de cada período, bem como o veículo $(k)$ que as realizaram. Relembrando que o $k=1$ representa as aeronaves.

Tabela 4.5: Rotas efetivamente realizadas.

\begin{tabular}{rrrrrrr}
\hline \multicolumn{2}{r}{ Período 1} & & Período 2 & & Período 3 \\
\cline { 1 - 3 } \cline { 6 - 7 } \cline { 6 - 6 } Rota & $k$ & Rota & $k$ & & Rota & $k$ \\
\hline$(7,6,8)$ & 1 & $(1,11,9,19)$ & 1 & $(7,23)$ & 1 \\
$(7,3)$ & 1 & $(1,7)$ & 1 & & $(23,24)$ & 1 \\
$(1,11,9,19)$ & 1 & $(7,23)$ & 1 & $(23,25)$ & 1 \\
$(1,4,22,1)$ & 6 & $(7,26)$ & 1 & $(23,26)$ & 1 \\
$(1,7,20,17$, & 10 & $(7,6)$ & 1 & $(7,20,16)$ & 1 \\
$12,1)$ & & & & & \\
$(1,5,1)$ & 9 & $(1,20,17,16)$ & $\mathrm{RE}$ & $(7,6,8)$ & 1 \\
$(1,2,1)$ & 9 & $(1,2,13,22,1)$ & 10 & & $(1,11,9,19)$ & 1 \\
$(1,14,18,1)$ & 3 & & & & $(1,7)$ & $\mathrm{RE}$ \\
$(1,13,1)$ & 2 & & & $(1,12)$ & $\mathrm{RE}$ \\
\hline
\end{tabular}

Ressalta-se que no período 2 houve a inclusão de uma RE efetuando a rota $(1,20,17,16)$. Já no período 3, além de uma RE cumprindo o trecho $(1,12)$, os locais: $2,5,10,13,14,18,21$ e 22 postergaram o recebimento para o próximo ciclo de planejamento. Além disso, excepcionalmente neste período, houve substituição da aeronave que realiza a LAP $2(1,7)$ para outra de maior capacidade, contudo, que possui maior custo aéreo. Embora não sejam frequentes, existe a possibilidade do órgão receber informações que afetam o planejamento inicialmente realizado e nem sempre há tempo hábil para refazer as rotas.

Nos casos de existência de RE, a decisão do órgão é de utilizar a capacidade máxima ofertada pela aeronave e informar ao responsável pelo transporte da carga que ela já fora levada para o destino. Quando há a possibilidade de postergação da entrega, o órgão avalia a entrega, de acordo com a disponibilidade de motoristas e de veículos.

Diante dessas incertezas, nos períodos 2 e 3 realizaram-se as análises considerando as seguintes hipóteses: i) o órgão detém apenas os dados do planejamento inicial, ou seja, não há a possibilidade de executar o modelo quando houver mudanças; e ii) o planejamento pode ser refeito sempre que novas informações forem adicionadas. 


\section{Resultados}

Neste capítulo estão presentes a aplicação do método, os resultados do teste de validação do modelo, bem como a sua execução nos três períodos. Posteriormente, serão realizados os comentários e reflexões acerca dos experimentos.

\section{1}

\section{Aplicação}

O modelo foi aplicado no Gurobi 9.0.2, em linguagem Julia 1.0.5, como resolvedor de MILP. Para tanto, utilizou-se um computador com processador Intel Core i7-8700K CPU 3.70 GHz; 64 MB de memória RAM e sistema operacional Ubuntu Linux, 64 bits, com o emprego de 1 núcleo. O tempo de execução do modelo foi definido para, no máximo, 10.800 segundos (3 horas).

\section{2}

\section{Velocidade e análise de viabilidade}

Inicialmente, foi realizado um teste de validação do modelo por meio de um caso fictício, utilizando-se dados aleatórios com demandas em todos os 25 locais. O FC foi definido como $0 \%$ para a utilização completa das LAP. As demandas 16, 18 e 20 foram consideradas indivisíveis para fins de elegibilidade. O tempo de execução atingiu o limite, deixando um gap de 6,6\% entre a melhor solução inteira encontrada e o limite inferior.

A Tabela 5.1 resume todas as rotas resultantes da otimização das demandas fictícias. Na primeira coluna (Rota) estão os pontos percorridos pelos veículos que estão na coluna seguinte $(k)$; na terceira coluna constam as demandas transportadas pelo veículo; nas próximas duas colunas (Peso e Vol), as restrições de capacidades aérea e terrestre, respectivamente, sendo que o valor entre parênteses demonstra o limite máximo de acordo com a categoria do veículo e; na última coluna (TC), demonstra o tempo de ciclo do veículo e, novamente, entre parênteses estão os limites do $T C$, que é atualizado caso o veículo esteja continuando uma rota anterior. Esta tabela demonstra que todas as restrições foram respeitadas e, portanto, o modelo é válido. 
Tabela 5.1: Resultados do modelo com demandas aleatórias.

\begin{tabular}{|c|c|c|c|c|c|}
\hline Rota & $k$ & Demandas & Peso(lim) & Vol(lim) & TC(lim) \\
\hline$(1,7)$ & 1 & $\begin{array}{l}6,7,8,17 \\
22,24,26\end{array}$ & $2997(3000)$ & - & - \\
\hline$(7,3)$ & 1 & 3 & $563(9200)$ & - & - \\
\hline$(7,6,8)$ & 1 & 6,8 & $798(9200)$ & - & - \\
\hline$(7,20,16)$ & 1 & 20,16 & $927(24163)$ & - & - \\
\hline$(1,11,9,19)$ & 1 & $11,9,19$ & $1645(1700)$ & - & - \\
\hline$(7,22)$ & 1 & 15,22 & $1028(1700)$ & - & - \\
\hline$(22,21)$ & 1 & 21 & $917(1700)$ & - & - \\
\hline$(7,23)$ & 1 & $23,24,25,26$ & $1991(24163)$ & - & - \\
\hline$(23,24)$ & 1 & 24 & $111(24163)$ & - & - \\
\hline$(23,25)$ & 1 & 25 & $477(24163)$ & - & - \\
\hline$(23.26)$ & 1 & 26 & $683(24163)$ & - & - \\
\hline$(1,18,1)$ & 3 & 18 & - & $36,0(118,6)$ & $14,4(120,0)$ \\
\hline$(1,4,7)$ & 4 & $\begin{array}{r}3,12,15,16 \\
20,23,25\end{array}$ & - & $84,0(85,0)$ & $19,5(120,0)$ \\
\hline$(7,12,17,1)$ & 4 & 12,17 & - & $58,0(85,0)$ & $86,8(100,5)$ \\
\hline$(1,2,14.22)$ & 5 & $2,4,14,21$ & - & $77,0(85,0)$ & $14,3(120,0)$ \\
\hline$(22,15)$ & 5 & 4,15 & - & $21,0(85,0)$ & $0,4(105,4)$ \\
\hline$(15,4,1)$ & 5 & 4,15 & - & $21,0(85,0)$ & $7,7(105,3)$ \\
\hline$(1,10,13,1)$ & 7 & 10,13 & - & $63(63,8)$ & $28,2(120,0)$ \\
\hline$(1,5,1)$ & 11 & 5 & - & $17,0(36,6)$ & $0,9(120,0)$ \\
\hline
\end{tabular}

A Tabela 5.2 demonstra os mesmos resultados da Tabela 5.1, ordenadas pelo fluxo do pedido do depósito até o cliente. Na primeira coluna estão os locais de destino do pedido $p$. Nas colunas seguintes estão, respectivamente, as rotas e os veículos que realizaram o transporte. Importante salientar que, nos pedidos em que houve mais de uma rota (Rota 2 e/ou Rota 3 ), significa que houve transbordo da carga do veículo $k 1$ para o $k 2$ e $k 3$.

\section{3}

\section{Comparação dos Resultados}

Os custos resultantes do modelo estão presentes na Tabela 5.3, que está dividida em duas etapas: a primeira contendo os resultados do modelo (com o planejamento original) e a última, contendo os resultados do modelo com as informações precisas. Em cada uma das fases foi incluído o valor da $F O$ de todos os períodos, o gap (em porcentagem) e o tempo de resolução (T) em segundos, para os FC iguais a $0 \%, 10 \%$ e $20 \%$.

É importante destacar as variações ocorridas nos períodos 2 e 3, relatadas na Subseção 4.3.4. Em ambos os dias, foram testadas tanto as demandas com o planejamento original (sem as RE, troca de aeronave e adiamento da entrega), como também foram realizadas as iterações considerando que o órgão detivesse as informações precisas.

O tempo de resolução foi sensível sob dois aspectos: a quantidade de locais a serem atendidos e o $F C$. Avaliando-se o primeiro fator, a otimização foi 
Tabela 5.2: Fluxo do pedido

\begin{tabular}{rrrrrrr}
\hline $\boldsymbol{p}$ & Rota 1 & $\boldsymbol{k 1}$ & Rota 2 & $\boldsymbol{k 2}$ & Rota 3 & $\boldsymbol{k 3}$ \\
\hline 2 & $(1,2)$ & 5 & - & - & - & - \\
3 & $(1,4,7)$ & 4 & $(7,3)$ & 1 & - & - \\
4 & $(1,2,14,22,15,4)$ & 4 & - & - & - & - \\
5 & $(1,5)$ & 11 & - & - & - & - \\
6 & $(1,7)$ & 1 & $(7,6)$ & 1 & - & - \\
7 & $(1,7)$ & 1 & - & - & - & - \\
8 & $(1,7)$ & 1 & $(7,6,8)$ & 1 & - & - \\
9 & $(1,11,9)$ & 1 & - & - & - & - \\
10 & $(1,10)$ & 7 & - & - & - & - \\
11 & $(1,11)$ & 1 & - & - & - & - \\
12 & $(1,4,7,12)$ & 4 & - & - & - & - \\
13 & $(1,10,13)$ & 7 & - & - & - & - \\
14 & $(1,2,14)$ & 5 & - & - & - & - \\
15 & $(1,2,14,22,15)$ & 5 & - & - & - & - \\
16 & $(1,4,7)$ & 4 & $(7,20,16)$ & 1 & - & - \\
17 & $(1,7)$ & 1 & $(7,12,17)$ & 4 & - & - \\
18 & $(1,18)$ & 3 & - & - & - & - \\
19 & $(1,11,9,19)$ & 1 & - & - & - & - \\
20 & $(1,4,7)$ & 4 & $(7,20,16)$ & 1 & - & - \\
21 & $(1,2,14,22)$ & 5 & $(22,21)$ & 1 & - & - \\
22 & $(1,7)$ & 1 & $(7,22)$ & 1 & - & - \\
23 & $(1,4,7)$ & 4 & $(7,23)$ & 1 & - & - \\
24 & $(1,7)$ & 1 & $(7,23)$ & 1 & $(23,24)$ & 1 \\
25 & $(1,4,7)$ & 4 & $(7,23)$ & 1 & $(23,25)$ & 1 \\
26 & $(1,7)$ & 1 & $(7,23)$ & 1 & $(23,26)$ & 1 \\
\hline & & & & & &
\end{tabular}

Tabela 5.3: Custos resultantes do modelo.

Modelo Otimizado com informações do planejamento original

\begin{tabular}{|c|c|c|c|c|c|c|c|c|c|}
\hline \multirow[b]{2}{*}{$\mathrm{FC}$} & \multicolumn{3}{|c|}{ Período 1} & \multicolumn{3}{|c|}{ Período 2} & \multicolumn{3}{|c|}{ Período 3} \\
\hline & $\mathrm{FO}$ & gap & $\mathrm{T}$ & $\mathrm{FO}$ & gap & $\mathrm{T}$ & FO & gap & $\mathrm{T}$ \\
\hline $0 \%$ & $25.378,6$ & $0,0 \%$ & 3.639 & $13.180,6$ & $0,0 \%$ & 4 & $21.924,3$ & $24,3 \%$ & 10.800 \\
\hline $10 \%$ & $36.481,4$ & $6,5 \%$ & 10.800 & $41.394,7$ & $0,0 \%$ & 28 & $69.446,4$ & $3,5 \%$ & 10.800 \\
\hline $20 \%$ & $46.809,3$ & $26,0 \%$ & 10.800 & $67.019,0$ & $0,0 \%$ & 28 & $114.783,8$ & $4,2 \%$ & 10.800 \\
\hline \multicolumn{10}{|c|}{ Modelo otimizado com informações precisas } \\
\hline & \multicolumn{3}{|c|}{ Período 1} & \multicolumn{3}{|c|}{ Período 2} & \multicolumn{3}{|c|}{ Período 3} \\
\hline $\mathrm{FC}$ & FO & gap & $\mathrm{T}$ & FO & gap & $\mathrm{T}$ & FO & gap & $\mathrm{T}$ \\
\hline $0 \%$ & $25.378,6$ & $0,0 \%$ & 3.639 & $2.145,3$ & $0,0 \%$ & 1 & 0,0 & $0,0 \%$ & 1 \\
\hline $10 \%$ & $36.481,4$ & $6,5 \%$ & 10.800 & $41.394,7$ & $0,0 \%$ & 101 & $64.047,4$ & $0,0 \%$ & 64 \\
\hline $20 \%$ & $46.809,3$ & $26,0 \%$ & 10.800 & $67.019,0$ & $0,0 \%$ & 48 & $110.379,1$ & $0,0 \%$ & 594 \\
\hline
\end{tabular}


alcançada no período 2 e no período 3 (apenas com as informações precisas), em virtude de haver, respectivamente, 11 e 13 destinos. Nas demais iterações, a quantidade de locais variaram entre 19 (período 1) e 22 (período 3).

Sob outra ótica, nos demais períodos houve variação dos gaps de 0,0\% até $26,0 \%$, conforme se alterou o $F C$. Enquanto no período 1 o gap aumentou com o acréscimo do $F C$; no período 3 ocorreu uma distorção inesperada, já que para o $F C=0 \%$, o gap atingiu o pico de $24,3 \%$, e reduziu-se vertiginosamente $(3,5 \%)$ quando o $F C=10 \%$ e posteriormente, teve leve aumento $(4,2 \%)$ quando o $F C=20 \%$. Sendo assim, percebe-se apenas que o $F C$ influencia no tempo de resolução, entretanto, não há a possibilidade de obter uma conclusão sobre a correlação entre eles.

A aferição dos ganhos com a otimização foi feita conforme a Equação (5-1), com a subtração do custo das RER $\left(C_{R}\right)$ da função objetivo $F O$ e dividindo-a pelo próprio $C_{R}$.

$$
\text { Ganho }=\frac{C_{R}-F O}{C_{R}}
$$

A Tabela 5.4 apresenta a porcentagem de ganho do modelo em relação aos trajetos não-otimizados. Em cada um dos períodos, a primeira coluna consta o $F C$, em porcentagem, a segunda refere-se ao $C_{R}$. As colunas G1 e G2 contêm, respectivamente, os ganhos percentuais entre o custo original e das $F O$ da otimização original (FO 1) e da otimização com as informações precisas (FO 2). Destaca-se que no período 1, como não houve alterações extraordinários no planejamento original, não há a coluna para o G2.

Observa-se que no período 2, quando o $F C=0 \%$ (transporte aéreo é gratuito) o G1 foi negativo. Isso ocorreu porque, no caso real, houve 3 demandas atendidas por RE; enquanto o modelo, sem as informações precisas, decidiu por atender esses 3 locais por caminhões. O mesmo aconteceu no período 3, com as postergações de entregas e com as RE, quando todas as cargas foram transportadas por aeronaves e, em consequência, o $C_{R}$ foi zero. Por esse motivo, o G1 seria -21.924,30/0, sendo considerado como N/A (não se aplica).

A Figura 5.1 demonstra os resultados da Tabela 5.4 em um gráfico que contém um comparativo entre o $C_{R}$, FO 1 e FO 2.

Tabela 5.4: Ganhos do modelo em relação às rotas efetivamente realizadas.

\begin{tabular}{|c|c|c|c|c|c|c|c|c|}
\hline \multirow[b]{2}{*}{$\mathrm{FC}$} & \multicolumn{2}{|c|}{ Período 1} & \multicolumn{3}{|c|}{ Período 2} & \multicolumn{3}{|c|}{ Período 3} \\
\hline & $C_{R}$ & G1 & $C_{R}$ & G1 & G2 & $C_{R}$ & G1 & G2 \\
\hline $0 \%$ & $29.924,3$ & 14,0 & $4.831,3$ & $-172,8$ & $\overline{55,6}$ & 0,0 & $\mathrm{~N} / \mathrm{A}$ & 0,0 \\
\hline $10 \%$ & $40.173,2$ & 9,2 & $52.603,0$ & 21,3 & 21,3 & $79.095,7$ & 12,2 & 19,0 \\
\hline $20 \%$ & $50.422,0$ & 7,2 & $100.374,6$ & 33,2 & 33,2 & $158.191,4$ & 27,4 & 30,2 \\
\hline
\end{tabular}




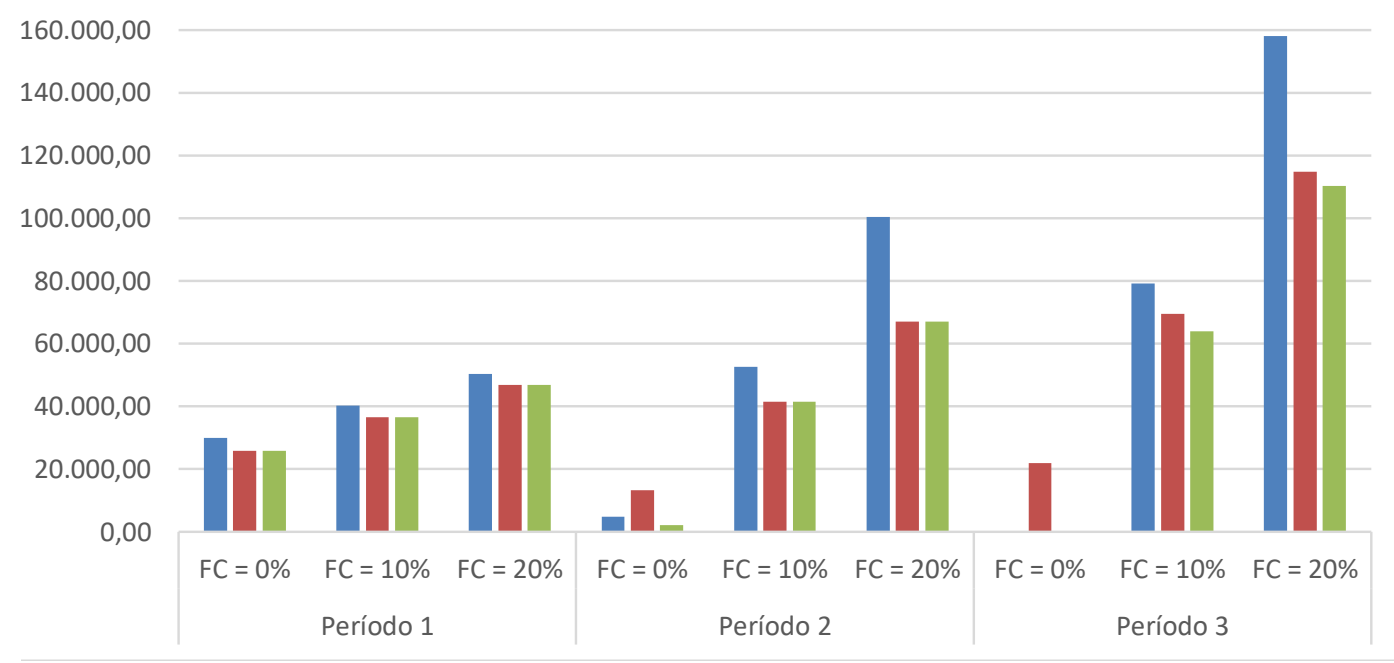

Figura 5.1: Representação gráfica dos custos totais das rotas.

Fonte: $\mathrm{O}$ autor.

\section{4}

\section{Discussões}

Os resultados indicam que o $F C$ é preponderante na decisão de se utilizar o modal aéreo, pois a quantidade de locais atendidos por aeronaves reduz expressivamente na medida em que o $F C$ aumenta. Além disso, com o $F C$ acima de $20 \%$, apenas áreas remotas são atendidas unicamente por aeronaves. A Tabela 5.5 sintetiza o modal utilizado para atendimento das demandas de cada período com as rotas otimizadas (sem informações precisas). A primeira linha indica o $F C$ aplicado. As próximas linhas, respectivamente, estão as quantidades de demandas atendidas exclusivamente por caminhão (Cam); caminhões e aeronaves com transbordo (Tr); e somente aeronaves (Aer).

Tabela 5.5: Quantidade de locais atendidos por modal.

\begin{tabular}{|c|c|c|c|c|c|c|c|c|c|}
\hline \multirow[b]{2}{*}{$\mathrm{FC}$} & \multicolumn{3}{|c|}{ Período 1} & \multicolumn{3}{|c|}{ Período 2} & \multicolumn{3}{|c|}{ Período 3} \\
\hline & $0 \%$ & $10 \%$ & $20 \%$ & $0 \%$ & $10 \%$ & $20 \%$ & $0 \%$ & $10 \%$ & $20 \%$ \\
\hline Cam & 7 & 17 & 19 & 3 & 7 & 7 & 7 & 14 & 15 \\
\hline $\operatorname{Tr}$ & 4 & 2 & 0 & 0 & 2 & 2 & 8 & 5 & 4 \\
\hline Aer & 8 & 0 & 0 & 8 & 2 & 2 & 7 & 3 & 3 \\
\hline
\end{tabular}

Em relação aos ganhos, o modelo demonstra grandes capacidades de redução de custos (ressalta-se o ganho de $55 \%$ no período 2, com as informações precisas e $F C=0 \%$ ). Os principais motivos que explicam a probabilidade de economia são: i) embora o custo de transporte terrestre seja muito inferior ao aéreo, o órgão utiliza extensivamente o segundo modal; e ii) o CL emprega vários caminhões para cumprir pequenas rotas, ao invés de consolidá-las em uma única viagem. Esses dois pontos podem ser observados através da Tabela 
5.6, a qual demonstra um comparativo entre as rotas otimizadas (R Otim) e as RER do período 1 , para o $F C=10 \%$.

Tabela 5.6: Comparação entre as rotas otimizadas e realizadas do Período 1 $($ para $\mathrm{FC}=10 \%)$

\begin{tabular}{rcrrrr}
\hline RER & $k$ & Custo & R Otim & $k$ & Custo \\
\hline$(7,3)$ & 1 & $5.039,5$ & $(7,3)$ & 1 & $5.039,5$ \\
$(7,6,8)$ & 1 & $3.490,8$ & $(9,19)$ & 1 & 321,3 \\
$(1,11,9,19)$ & 1 & $1.718,5$ & $(1,13,1)$ & 2 & $3.462,83$ \\
$(1,13,1)$ & 2 & $3.462,8$ & $(1,20,17,16$, & 10 & $14.265,2$ \\
& & & $12,1)$ & & \\
$(1,14,18,1)$ & 3 & $2.374,7$ & $(1,5,2,14,18)$ & 11 & $1.214,3$ \\
$(1,4,22,1)$ & 6 & $2.483,8$ & $(18,10,11,9,8)$ & 11 & $6.495,0$ \\
$(1,5,1)$ & 8 & 138,0 & $(8,6,7,22,4,1)$ & 11 & $5.683,2$ \\
$(1,2,1)$ & 9 & 336,6 & & & \\
$(1,7,20,17$, & 10 & $21.130,3$ & & & \\
$16,12,1)$ & & & & & $36.481,4$ \\
\hline Total & $40.173,2$ & Total
\end{tabular}

A única ressalva a se refletir é quando ocorrem alterações no planejamento inicial, ou seja, nos casos da existência das RE, demandas postergadas ou alteração de aeronaves. Nessas condições, exclusivamente quando o $F C=0 \%$, o modelo retornou soluções piores, ocasionados pelas possibilidades de entregas gratuitas (nas RER) através das RE que, por sua vez, são consideradas somente quando são inseridas as informações precisas. Portanto, recomenda-se que, caso haja a possibilidade, o gestor refaça o planejamento das rotas sempre que for noticiado novos elementos. Dessa forma, os ganhos com a otimização serão expressivamente ampliados.

Diante do exposto, observa-se que o modelo é sensível sob duas perspectivas: a primeira é em relação ao $F C$, o qual se mostrou crucial tanto para o cálculo do custo total de transporte, quanto para a decisão de utilizar o modal aéreo, terrestre ou híbrido (com transbordo); e a segunda à detenção das informações precisas acerca dos voos extraordinários e das demandas postergadas. 


\section{6}

\section{Conclusão}

As operações aeroterrestres viabilizaram o comércio internacional para os clientes que demandam curto prazo de entrega. Entretanto, como a concorrência se torna cada vez mais acirrada, ser competitiva apenas na produção não garante a sobrevivência da empresa. É necessária uma gestão eficiente em todos os ramos logísticos. Diante disso, dado o alto custo operacional dos transportes aéreos, a otimização de suas rotas traduz em grandes oportunidades de economia.

Por esse motivo, foi introduzido nessa dissertação o HALRPPA, atendendo completamente o escopo delimitado neste estudo, ou seja, no roteamento intermodal (aeroterrestre) de transporte de cargas, de empresas que possuem frota própria para ambos os modais. Posteriormente, o modelo foi aplicado em um órgão governamental, no planejamento real de três períodos não-consecutivos e, como resultado, retornou expressivas reduções de custos (7\% a $55 \%$, caso o modelo seja resolvido com as informações precisas).

Em relação ao tempo de resolução, nos períodos com menores quantidades de locais (11 e 13), o modelo alcançou a otimização. Contudo, quando o planejamento envolve uma quantidade de destinos superior a 19, o modelo atinge o limite de tempo de solução (três horas). Além disso, o $F C$ influencia na celeridade mas, aparentemente, não há correlação entre o tempo de resolução e o FC.

Ademais, conforme destacado no Capítulo 4, o modelo não leva em consideração as restrições legais de jornada de trabalho o que, invariavelmente, reduziria a quantidade de locais atendidas por rotas. Além disso, a questão do pickup-and-delivery também influencia diretamente no planejamento, já que a formulação apresentada contemplou apenas as entregas dos materiais disponíveis no depósito central.

Embora haja a necessidade de incorporar ao modelo algumas restrições para melhor adequar à realidade enfrentada no mundo real, a partir deste estudo é possível obter conclusões relevantes acerca do roteamento intermodal de cargas. Primeiramente, a importância do órgão refazer todo o planejamento quando há a inserção de RE, substituição de aeronaves ou postergação de demandas. Em sequência, considerando o alto custo absoluto do modal aéreo, é crucial que o órgão possua claramente definida qual o $F C$, ou seja, a porcentagem de 
importância atribuída à utilização de aeronaves (os aviões já estariam realizando os trajetos para outros fins? Ou as LAP foram definidas exclusivamente para o transporte de cargas?). Ademais, outro ponto levantado é a possibilidade do $F C$ não se limitar a um valor fixo para todas as rotas aéreas, mas sim, calculado especificamente para cada rota ou parte dela. Por fim, a oportunidade de ganho com o emprego mais eficiente das rotas terrestres, através da consolidação de vários trajetos curtos em uma única rota, utilizando-se melhor a capacidade disponível dos veículos. Embora aparentemente se mostre uma questão trivial, esse estudo demonstra a importância do gestor de operações possuir sistemas de informação adequados para a confecção do planejamento e a execução das entregas.

Diante disso, podemos elencar os seguintes estudos futuros que podem contribuir com essa dissertação: i) desenvolvimento de heurísticas ou metaheurísticas para buscar soluções mais rápidas e com a capacidade de contemplar maior quantidade de demandas e, posteriormente, comparar os resultados com o objetivo de realizar uma reflexão entre o trade-off velocidade e qualidade da solução; ii) inclusão de restrições que aproximam ainda mais o modelo apresentado aos problemas enfrentados no mundo real; e iii) elaboração de métricas para o cálculo do $F C$ e a possibilidade do $F C$ se tornar flexível. 


\section{Referências Bibliográficas}

Agência Nacional de Aviação Civil (2019). Anuário do transporte aéreo. https: //www. anac.gov.br. Acesso em: 2020-14-06.

Ahuja, R., Magnanti, T., e Orlin, J. (1993). Network Flows. Prentice-Hall, US., Upper Saddle River, NJ.

Archetti, C. e Peirano, L. (2020). Air intermodal freight transportation: The freight forwarder service problem. Omega, 94:15.

Arroyo, J. E. C. (2002). Heurísticas e Metaheurísticas para Otimização Combinatória Multiobjetivo. PhD thesis, Universidade Estadual de Campinas, Campinas, SP.

Baldacci, R., Hadjiconstantinou, E., e Mingozzi, A. (2004). An exact algorithm for the capacitated vehicle routing problem based on a two-commodity network flow formulation. Operations Research, 52:723-738.

Braekers, K., Ramaekers, K., e Nieuwenhuyse, I. V. (2016). The vehicle routing problem: State of the art classification and review. Computers $\&$ Industrial Engineering, 99:300-313.

BRASIL (2020). Ministério da Defesa. Força Aérea Brasileira: C-99, C-130 e C-97 realizam Transporte Aéreo Logístico nesta quarta-feira. https://www.fab.mil. br. Acesso em: 2020-21-07.

Chang, T. S. (2008). Best routes selection in international intermodal networks. Computers \& Operations Research, 35:2877-2891.

Chao, I.-M., Golden, B., e Wasil, E. (2016). A computational study of a new heuristic for the site-dependent vehicle routing problem. INFOR: Information Systems and Operational Research, 37(3):319-336.

Cho, J. H., Kim, H. S., e Choi, H. R. (2012). An intermodal transport network planning algorithm using dynamic programming - a case study: from busan to rotterdam in intermodal freight routing. Application Intelligence, 36(3):529-541.

Dantzig, G. B., Fulkerson, R., e Johnson, S. (1954). Solution of a large-scale travelingsalesman problem. Operations Research, 2:393-410.

Dantzig, G. B. e Ramser, J. H. (1959). The truck dispatching problem. Management Science, 6:80-91.

Desrochers, M. e Laporte, G. (1991). Improvements and extensions to the MillerTucker-Zemlin subtour elimination constraints. Operations Research Letters, 10:27-36. 
Drexl, M. (2013). A note on the separation of subtour elimination constraints in elementary shortest path problems. European Journal Of Operational Research, 229(3):595-598.

Ducharme, C. (2012). Modelagem e otimização do programa de manutenção de transformadores de potência. Dissertação (Mestrado em Engenharia Elétrica), Universidade Federal do Rio de Janeiro, Rio de Janeiro.

Erdoğan, G. (2017). An open source spreadsheet solver for vehicle routing problems. Computer \& Operations Research, 84:62-72.

Feng, B., Li, Y., e Shen, Z.-J. M. (2015). Air cargo operations: Literature review and comparison with practices. Transportation Research Part C, 56:263-380.

Fischetti, M. e Lodi, A. (2003). Local branching. Mathematical Programming, 98:23-47.

G1 (2014). Avião dos correios chega ao acre com 42 toneladas de encomendas. http://g1.globo.com. Acesso em: 2020-21-07.

Gavish, B. e Graves, S. C. (1982). Scheduling and routing in transportation and distribution systems: Formulations and new relaxations. Technical Report 8202, Graduate School of Management, University of Rochester.

Gilmore, D. (2002). Achieving transportation excellence. World Trade, 15(11):36-38.

Goldbarg, M. C. (2005). Otimização combinatória e programação linear: modelos e algoritmos. Elsevier, BR., Rio de Janeiro, RJ.

Golden, B. L., Assad, A. A., Levy, L., e Gheysens, F. (1984). The fleet size and mix vehicle routing problem. Computers \& Operations Research, 11:49-66.

Huang, K. e Chi, W. (2007). A lagrangian relaxation based heuristic for the consolidation problem of airfreight forwarders. Transportation Research Part $C$, $15: 235-245$.

Huang, K., Lee, Y.-T., e Xu, H. (2020). A routing and consolidation decision model for containerized air-land intermodal operations. Computers $\& 3$ Industrial Engineering, 141:10.

Instituto de Logística e Supply Chain (2017). Custos logísticos no brasil. http: //www.ilos.com.br. Acesso em: 2020-14-06.

Instituto Nacional de Estudos e Pesquisas Educacionais Anísio Teixeira (2020). Indicadores financeiros educacionais. http://inep.gov.br. Acesso em: 202030-06.

Irnich, S., Toth, P., e Vigo, D. (2014). The Family of Vehicle Routing Problems, Vehicle Routing: Problems, Methods, and Applications. Society for Industrial and Applied Mathematics, Philadelphia.

Kasilingam, R. (2003). Air cargo supply chain management and challenges. http://www . utdallas.edu/ metin/aircargo.pdf. Acessado: 2020-13-06.

Korte, B. e Vygen, J. (2000). Combinatorial optimization: theory and algorithms. Springer-Verlag, Berlim. 
Koç, Ç., Bektaş, T., Jabali, O., e Laporte, G. (2016). Thirty years of heterogeneous vehicle routing. European Journal of Operational Research, 249:1-21.

Laporte, G. (2007). What you should know about the vehicle routing problem. Naval Research Logistics, 54:811-819.

Laporte, G. (2009). Fifty years of vehicle routing. Transportation Science, 43:408-416.

Laporte, G. e Norbert, Y. (1987). Exact algorithms for the vehicle routing problem. Computers \& Industrial Engineering, 31:147-184.

Leung, L. C., Hui, Y. V., Wang, Y., e Chen, G. (2009). A 0-1 LP model for the integration and consolidation of air cargo shipments. Operations Research, $57(2): 402-412$.

Li, Z., Bookbinder, J. H., e Elhedhli, S. (2012). Optimal shipment decisions for an airfreight forwarder: Formulation and solution methods. Transportation Research Part C, 21:17-30.

Miller, C. E., Tucker, A., e Zemlin, R. (1960). Integer programming formulation of traveling salesman problems. Journal of the ACM, 7:326-329.

Pataki, G. (2003). Teaching integer programming formulations using the traveling salesman problem. SIAM REVIEW, 45(1):116-123.

Pecin, D., Pessoa, A., Poggi, M., e Uchoa, E. (2017). Improved branch-cut-andprice for capacitated vehicle routing. Mathematical Programming Computation, $9(1): 61-100$.

SteadieSeifi, M., Dellaert, N. P., Nuijten, W., Woensel, T. V., e Roufi, R. (2014). Multimodal freight transportation planning: A literature review. European Journal of Operational Research, 233(1):1-15.

Subramanian, A., Penna, P. H. V., Uchoa, E., e Ochi, L. S. (2012). A hybrid algorithm for the heterogeneous fleet vehicle routing problem. European Journal of Operational Research, 221:285-295.

Taillard, E. D. (1999). A heuristic column generation method for the heterogeneous fleet vehicle routing problem. Operations Research, 33:1-14.

Vidal, T., Laporte, G., e Matl, P. (2020). A concise guide to existing and emerging vehicle routing problem variants. European Journal of Operational Research, 286:401-416.

Yang, X., Low, J. M. W., e Tang, L. C. (2011). Analysis of intermodal freight from china to indian ocean: A goal programming approach. Journal of Transport Geography, 19:515-527. 